Article

\title{
Synthesis of Novel Shikonin Derivatives and Pharmacological Effects of Cyclopropylacetylshikonin on Melanoma Cells
}

\author{
Christin Durchschein ${ }^{1}$, Antje Hufner ${ }^{2}{ }^{-}$, Beate Rinner ${ }^{3}$, Alexander Stallinger ${ }^{3}$, \\ Alexander Deutsch ${ }^{4}$, Birgit Lohberger ${ }^{5}$, Rudolf Bauer ${ }^{1, *}{ }^{-}$and Nadine Kretschmer ${ }^{1}$ \\ 1 Institute of Pharmaceutical Sciences, Department of Pharmacognosy, University of Graz, \\ Universitaetsplatz 4, 8010 Graz, Austria; christin.durchschein@uni-graz.at (C.D.); \\ nadine.kretschmer@uni-graz.at (N.K.) \\ 2 Institute of Pharmaceutical Sciences, Department of Pharmaceutical Chemistry, University of Graz, \\ Universitaetsplatz 1, 8010 Graz, Austria; antje.huefner@uni-graz.at \\ 3 Division of Biomedical Research, Medical University of Graz, Roseggerweg 48, 8036 Graz, Austria; \\ beate.rinner@medunigraz.at (B.R.); alexander.stallinger@medunigraz.at (A.S.) \\ 4 Division of Hematology, Medical University of Graz, Auenbruggerplatz 15, 8036 Graz, Austria; \\ alexander.deutsch@medunigraz.at \\ 5 Department of Orthopedics and Trauma, Medical University Graz, Auenbruggerplatz 5, 8036 Graz, Austria; \\ birgit.lohberger@medunigraz.at \\ * Correspondence: rudolf.bauer@uni-graz.at; Tel.: +43-316-380-8700
}

Received: 9 October 2018; Accepted: 20 October 2018; Published: 30 October 2018

\begin{abstract}
Despite much research in the last centuries, treatment of malignant melanoma is still challenging because of its mostly unnoticeable metastatic spreading and aggressive growth rate. Therefore, the discovery of novel drug leads is an important goal. In a previous study, we have isolated several shikonin derivatives from the roots of Onosma paniculata Bureau \& Franchet (Boraginaceae) which evolved as promising anticancer candidates. $\beta, \beta$-Dimethylacrylshikonin (1) was the most cytotoxic derivative and exhibited strong tumor growth inhibitory activity, in particular, towards melanoma cells. In this study, we synthesized eighteen novel shikonin derivatives in order to obtain compounds which exhibit a higher cytotoxicity than 1 . We investigated their cytotoxic potential against various melanoma cell lines and juvenile skin fibroblasts. The most active compound was (R)-1-(1,4-dihydro-5,8-dihydroxy-1,4-dioxonaphthalen-2-yl)-4-methylpent-3-enyl cyclopropylacetate (cyclopropylacetylshikonin) (6). It revealed significant stronger tumor growth inhibitory activity towards two melanoma cell lines derived from metastatic lesions (WM164 and MUG-Mel2). Further investigations have shown that 6 induced apoptosis caspase-dependently, increased the protein levels of cleaved PARP, and led to double-stranded DNA breaks as shown by phosphorylation of H2AX. Cell membrane damage and cell cycle arrest were not observed.
\end{abstract}

Keywords: shikonin derivatives; cyclopropylacetylshikonin; apoptosis; melanoma

\section{Introduction}

Skin cancer is a major public health concern all over the world. According to the WHO, one of three diagnosed cancers is a skin cancer. Melanoma is the most dangerous type of skin cancer because of its often unnoticeable metastatic spreading and aggressive growth rate. Only approx. $4 \%$ of human skin cancers are melanoma but cause around $80 \%$ of all skin cancer deaths and mortality rates are increasing worldwide [1]. In early stages, skin-localized melanomas are complete removed by local surgery. However, advanced metastatic melanomas remain a challenge in treatment. 
Although progress in elucidating the genetic and molecular aberrations of this disease has been accomplished in recent years and novel drugs, such as vemurafenib (BRAF inhibitor), ipilimumab (anti-CTLA-4 monoclonal antibody), and nivolumab (anti-PD-1 antibody), have been approved, we are far from understanding the pathogenesis of this disease precisely [2]. In addition, it has to be remembered that medicinal treatments still have limited efficacy due to resistances of tumors, low response rates as well as adverse side effects [3]. In the development of new anticancer drugs, natural products have always played an important role. Approximately $87 \%$ of all approved small molecules anticancer drugs are natural products or are derived from them [4]. Famous natural products in this area are vinca alkaloids isolated from Catharantus roseus G. Don, like vinblastine and vincristine, anthracyclines from Streptomyces bacteria such as doxorubicin, and taxanes from different Taxus species, like paclitaxel and docetaxel. During the last decades, many studies have demonstrated the broad pharmacological spectrum of shikonin and derivatives, natural naphthoquinones derived from the roots of Chinese herbs such as Arnebia euchroma (Royle) I. M. Johnston, Lithospermum erythrorhizon Siebold \& Zuccarini, or Onosma paniculata Bureau \& Franchet. Traditionally, these roots are used to treat several diseases including cancer. In previous studies, roots of $O$. paniculata were phytochemically and pharmacologically investigated and emerged as promising research objects [5-8]. We were able to isolate several shikonin derivatives and investigated their effects on various tumor cell lines including leukemia, medullary thyroid carcinoma, glioblastoma, colon cancer, breast cancer, and melanoma [5-8]. Overall, $\beta, \beta$-dimethylacrylshikonin (1) was the most cytotoxic compound of all isolated derivatives. Interestingly, it exhibited the strongest cytotoxic activity against several melanoma cell lines [8]. Therefore, we decided to concentrate our studies on the effects in melanoma cells. We could show that it led to apoptosis induction by caspase activation as well as cell cycle arrest [8]. In general, the anticancer effects of shikonin derivatives are largely attributed to the induction of cell cycle arrest, apoptosis, and/or necroptosis and the inhibition of migration and invasion [8-11]. In this study, we are addressing the question of whether the structure of $\mathbf{1}$ can be modified to find derivatives which are more cytotoxic. In previous investigations, we confirmed that the naphtoquinone scaffold is more crucial for the entire activity than the side chain [12]. Moreover, the presence of phenolic hydroxyl groups increases the activity $[13,14]$ and the side chain seems to modify the entire activity [15-17]. We now have synthesized eighteen novel shikonin derivatives and evaluated their cytotoxic effects against various melanoma cell lines and skin fibroblasts. Finally, the pharmacological effects of the most active derivative were investigated in more detail.

\section{Results and Discussion}

\subsection{Synthesis of Novel Shikonin Derivatives}

Shikonin derivatives possess strong growth inhibitory activity towards various cancer cell lines [18-20]. In a previous investigation, we confirmed that the naphtoquinone scaffold is more crucial for the entire activity than the side chain [12]. However, there are indications that the side chain influences the entire activity [12,15-17]. The hydroxyl groups at the naphthazarin scaffold are necessary for maintaining its drug-like property. Also all known anthracycline antitumor antibiotics and mitoxantrone include a quinizarin skeleton with free hydroxyl groups. These might be important for DNA binding and cell or tissue bioavailability [21]. Therefore, we decided to modify the side chain of $\mathbf{1}$ which was the most cytotoxic derivative in a previous study [8]. To keep close to our lead compound 1, we formally connected the two methyls of dimethylacylate with one to four methylene groups resulting in the corresponding cycloalkylideneacetates 2 to 5 . The influence of the double bond was investigated by preparing cycloalkylacetates 6 to 9 and cyclohexenylacetate 10. To study the effect of the spacing $\mathrm{CH}$ resp. $\mathrm{CH}_{2}$ group, cyclopropyl to cyclohexylcarboxylates $\mathbf{1 1}$ to 14 together with the cyclohexenylcarboxylates $\mathbf{1 5}$ and $\mathbf{1 6}$ were synthesized. 3-methylcyclopropylcarboxylate $\mathbf{1 7}$ and bicyclic derivatives 18, 19, and 20 were produced to analyze the space filling of an additional methylene moiety (Table 1). 
Table 1. List of investigated shikonin esters.

\begin{tabular}{|c|c|c|c|}
\hline Cpd. & $\mathbf{R}$ & Cpd. & $\mathbf{R}$ \\
\hline 1 & & 11 & \\
\hline 2 & & 12 & \\
\hline 3 & & 13 & \\
\hline 4 & & 14 & \\
\hline 5 & & 15 & \\
\hline 6 & & 16 & \\
\hline 7 & & 17 & \\
\hline 8 & & 18 & \\
\hline 9 & & 19 & \\
\hline 10 & & 20 & \\
\hline
\end{tabular}

Since shikonin is easier and in bigger amounts acquirable than 1, we used shikonin as starting material for our synthesis. Shikonin (100\% R-isomer, seeSupplementary Material) was acylated as usual via Steglich esterification with the corresponding carboxylic acid, dicyclohexylcarbodiimide (DCC) as a coupling reagent and 4-dimethylaminopyridine (DMAP) as catalyst in dichloromethane (Scheme 1) [16,21-25]. As outlined in Scheme 2, cyclohexylideneacetic acid (4a) and cycloheptylideneacetic acid (5a) resulted from condensation of the corresponding cycloketone with chloroacetic acid mediated by sodium hydride and diethylphosphite [26]. Cyclobutylideneacetic acid (2a) and cyclopentylideneacetic acid (3a) were synthesized via Horner-Wadsworth-Emmons reaction [27] followed by hydrolysis with lithium hydroxide monohydrate in aqueous $\mathrm{THF} / \mathrm{MeOH}$ [28]. The $\mathrm{C}=\mathrm{C}$ double bond of ethyl cyclopentylideneacetate was partially isomerized resulting in a 1:3 mixture of cyclopentylideneacetic acid (3a) and 
2-cyclopentenylacetic acid (3b). $7 \mathbf{a}$ was prepared analogously to 3-ethylpentanoic acid via Grignard reaction using (bromomethyl)cyclobutane and carbon dioxide (Scheme 3) [29].<smiles>CC(C)=CC[C@@H](O)C1=CC(=O)c2c(O)ccc(O)c2C1=O</smiles>

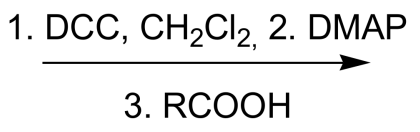<smiles>[R]C(=O)O[C@H](CC=C(C)C)C1=CC(=O)c2c(O)ccc(O)c2C1=O</smiles>

shikonin

Scheme 1. Acylation of shikonin.<smiles>O=C1CC[Te]C1</smiles>

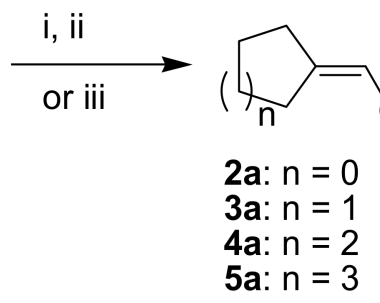<smiles>O=C(O)CC1=C[Te]CC1</smiles>
$3 b: n=1$

Scheme 2. Syntheses of cycloalkylideneacetic acids 2a to $5 \mathrm{a}$. (i) $(\mathrm{EtO})_{2} \mathrm{P}(\mathrm{O})-\mathrm{CH}_{2}-\mathrm{COOEt}, \mathrm{NaH}, \mathrm{Et}_{2} \mathrm{O}$, cyclobutanone or cyclopentanone (ii) $\mathrm{LiOH} \times \mathrm{H}_{2} \mathrm{O}, \mathrm{THF}, \mathrm{H}_{2} \mathrm{O}, \mathrm{MeOH}$, (iii) 1. $\mathrm{HP}(\mathrm{OMe})_{2}, \mathrm{NaH}$, $\mathrm{ClCH}_{2} \mathrm{COOH}$, cyclohexanone or cycloheptanone, glyme 2. $\mathrm{HCl}, \mathrm{H}_{2} \mathrm{O}$.
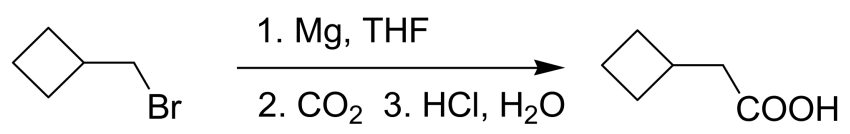

$7 a$

Scheme 3. Synthesis of cyclobutylacetic acid (3a).

\subsection{Cytotoxicity of Investigated Shikonin Derivatives}

Since all synthesized derivatives were $100 \% R$-isomers, the first question was if the chiral center influences the overall pharmacological activity. Therefore, different samples of $\mathbf{1}$ with varying enantiomeric ratios were prepared. Melanoma cells were treated with these compounds up to $10.0 \mu \mathrm{M}$ and for $72 \mathrm{~h}$ and the effect was compared to $\mathbf{1}$ (isolated from roots). We did not detect significant differences in the cytotoxicity indicating that the chiral center has no influence on the activity. In addition, it made no difference if the compound was synthesized (70/30 mixture) or isolated (see Figure S1, Supplementary Material).

Subsequently, all derivatives were investigated regarding their cytotoxicity against various melanoma cell lines (SBcl2, WM9, WM164, and MUG-Mel2) and juvenile skin fibroblasts. Cells were treated with different concentrations of 2 to 20 (Figure 1 and, additionally, Figures S2 and S3, Supplementary Material) and their effects compared to 1. SBcl2 cells represent an early state of cancer progression (cutaneous melanoma, radial growth phase) and are very sensitive to $\mathbf{1}$ and many other compounds. WM9, WM164, and MUG-Mel2 are derived from melanoma metastases located at the left axillary node (BRAF mutated), right upper arm with stage IV superficial spreading melanoma (BRAF mutated), and from very fast growing metastasis of the left shoulder (NRAS mutated), respectively [30]. Especially WM164 and MUG-Mel2 cells are less susceptible to many cytotoxic compounds and, therefore, difficult to treat. This is also reflected by our results. For example, compounds 2, 4, and 7 were considerably less cytotoxic towards WM164 and MUG-Mel2 cells than towards the other cell lines. However, this does not apply to all cycloalkylidenes and cycloalkylacetates. The assumption that an increase of steric bulkiness results in decreased cytotoxic activity [16] does 
not apply to the cytotoxicity of our cycloalkylideneacetates series $\mathbf{2}$ to $\mathbf{5}$ with $\mathbf{5}$ as the most potent one. This regularity was also not strictly observed for cycloalkylacetates $\mathbf{6}$ to 9 and cycloalkane carboxylates 11 and 14.

Cyclopropylacetate 6 turned out to be significantly more active against the metastatic cell lines WM164 and MUG-Mel2 than 1 (Table 2). This is of special interest because these kinds of cells cause major clinical problems and respond poor to most treatment options. 6 was also more cytotoxic against the melanoma cell lines used than 11, which was the most active derivative in a previous study [20]. However, it also exhibited cytotoxicity against juvenile skin fibroblasts $\left(\mathrm{IC}_{50}=1.6 \pm 0.4 \mu \mathrm{M}\right)$. To better assess its cytotoxicity against nontumorigenic cells, 6 was also tested on two other healthy cell types. On the one hand, human embryonic epithelial cells (HEK-293), a well-established nontumorigenic cell line, was used. On the other hand, we used isolated human adult fibroblasts to study the cytotoxicity against another type of fibroblasts. Fibroblasts have been shown to display distinct transcriptional patterns depending on their origin [31]. Compared to juvenile fibroblasts, $\mathrm{IC}_{50}$ values of 6 were 3.4 fold higher towards HEK-293 cells $\left(\mathrm{IC}_{50}=5.4 \pm 0.7 \mu \mathrm{M}\right)$ and 4.0 fold higher against adult fibroblasts $\left(\mathrm{IC}_{50}=6.4 \pm 0.7 \mu \mathrm{M}\right)$. This shows that the cytotoxicity varies in different nontumorigenic types of cells. Nevertheless, toxicity of chemotherapeutics to healthy cells is a well-known problem in cancer therapy and leads to undesirable side effects in patients. For example, vinblastine, a commonly used chemotherapeutic, exhibited $\mathrm{IC}_{50}$ values towards melanoma cells and lung fibroblasts within the same concentration range [8]. Another example is doxorubicin-again a commonly used chemotherapeutic-which showed the same or even a higher cytotoxicity against HEK-293 cells than against breast cancer and leukemia cells [32,33]. However, quinones and derivatives are also members of the PAINS group. PAINS (Pan-Assay Interference Compounds) possess common structural motifs that lead to strong activities in biological assays. PAINS structures occur in natural products (e.g., vitamin K2 and thymoquinone) as well as synthetic drugs. Even some approved chemotherapeutics such as mitoxantrone and doxorubicin contain a PAINS motif. PAINS structures lead, for example, to reactions with nucleophiles such as thiols or amines and cause redox cycling. Quinones including shikonin derivatives possess strong redox activity. Therefore, they can react with nucleophiles, for example, in the side chains of proteins [34]. This, in turn, can lead to adverse side effects. To overcome or reduce these adverse effects, one might be tempted to use smart 6-loaded targeted nanoparticles. It has been reported that blood vessels of tumors are leaky allowing nanoparticles to penetrate specifically into the tumor tissue. In addition, lymphatic drainage in tumors is poor retaining the accumulated nanoparticles and allowing the drug to be released [35]. Moreover, shikonin-loaded nanoparticles improved the antitumor effects of shikonin in glioma cells in vitro and the particles accumulated in the brain of rats [36]. For melanoma, it has been demonstrated recently that self-assembled nanomicelles of clotrimazole improve drug delivery and apoptosis and, at the same time, inhibit tumor progression [37]. Therefore, we assume that this might be a promising way for further development of $\mathbf{6}$. However, development, characterization as well as in vitro and in vivo testing of such nanoparticles goes beyond the scope of the current work.

Returning to the structure activity relationship of our synthesized compounds, methylation of the cyclopropane moiety of $\mathbf{1 1}$ further reduced the activity (see compound 17). An additional double bond in the carbocyclus, as present in compounds 10,15 and 16, did not enhance cytotoxicity and, compared to the corresponding monocyclic derivative, an additional methylene bridge as presented in the bicyclic derivatives $\mathbf{1 8}$ to 20 provides no regularity concerning activity.

In summary, $(R)-1$-(1,4-dihydro-5,8-dihydroxy-1,4-dioxonaphthalen-2-yl)-4-methylpent-3-enyl cyclopropylacetate (cyclopropylacetylshikonin, 6) was the most active derivative of this series. The $\mathrm{IC}_{50}$ values towards the metastatic cell lines WM164 and MUG-Mel2 were 1.7 fold (WM164, $p=0.05)$ and 2.3 fold (MUG-Mel2, $p \leq 0.001$ ) lower than those of 1 , while the effectiveness against the other melanoma cell lines was similar compared to $\mathbf{1}$ (Table 2 ). 


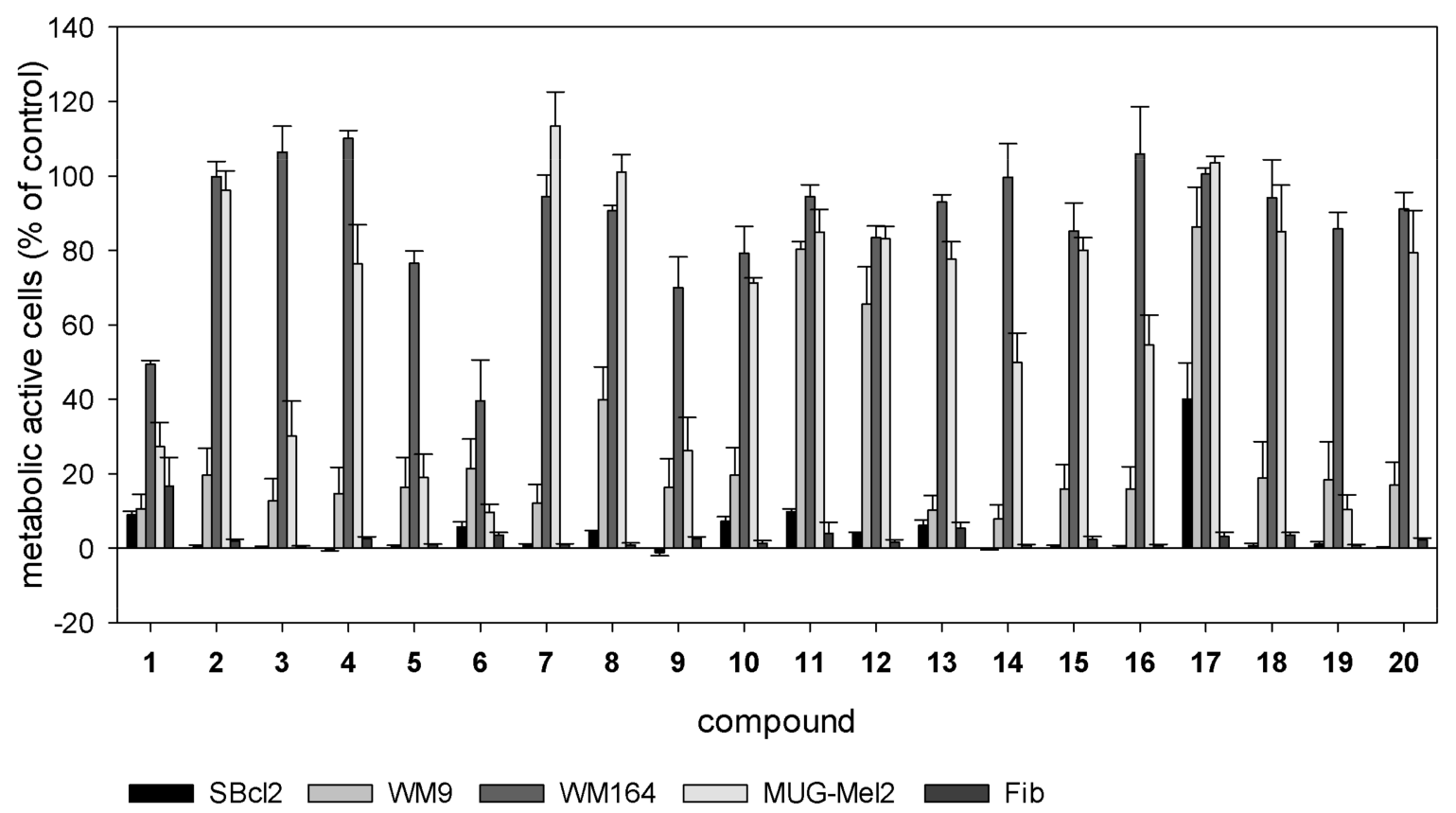

Figure 1. Results of the XTTassay. Melanoma cells (SBcl2, WM9, WM164, and MUG-Mel2) and juvenile skin fibroblasts were treated with $5.0 \mu \mathrm{M}$ of 2 to 20 for $72 \mathrm{~h}$ (mean $\pm \mathrm{SEM}, n=4$ ). Compound 1 serves as reference compound. Results of all tested concentrations can be found in the Supplementary Material.

Table 2. $\mathrm{IC}_{50}$ values $(\mu \mathrm{M})$ after $72 \mathrm{~h}$ treatment with 1 or 6 (mean $\left.\pm \mathrm{SEM}, n=4\right)$. $\mathrm{IC}_{50}$ values were determined using the four-parameter logistic curve and individual values of all independent experiments.

\begin{tabular}{ccccc}
\hline Compound & SBcl2 & WM9 & WM164 & MUG-Mel2 \\
\hline $\mathbf{1}$ & $1.1 \pm 0.1$ & $2.7 \pm 0.3$ & $8.3 \pm 0.3$ & $7.2 \pm 0.5$ \\
$\mathbf{6}$ & $0.9 \pm 0.7$ & $3.2 \pm 0.8$ & $4.9 \pm 1.7$ & $3.2 \pm 0.3$ \\
\hline
\end{tabular}

\subsection{Pharmacological Effects of Cyclopropylacetylshikonin (6)}

Since 6 revealed the strongest growth inhibitory activity towards the melanoma cell lines used, its pharmacological effects were investigated in more detail. Figure 2 summarizes the results of the ApoToxGlo ${ }^{\mathrm{TM}}$ assay. This assay determines cell viability, compound cytotoxicity, and the activity of caspase 3/7, indicative for apoptosis induction, simultaneously in the same well. Cell viability of WM9 and MUG-Mel2 was slightly reduced after $24 \mathrm{~h}$ at $7.5 \mu \mathrm{M}$ (Figure 2A). However, this change was not statistically significant. WM164 cells showed no reduction of cell viability but a slight, however, again not statistically significant increase. Cytotoxicity was minimally decreased in all cell lines after $48 \mathrm{~h}$ (Figure 2B). Caspase 3/7 activity peaked after $24 \mathrm{~h}$ with the maximum at $5.0 \mu \mathrm{M}$ and $7.5 \mu \mathrm{M}$ (Figure 2C). The strongest activation was found for WM9 cells. In WM164, there was just a marginal increase in caspase 3/7 activity. In previous investigations, we demonstrated that 1 also induced apoptosis caspase 3 dependently after $24 \mathrm{~h}$ [8]. The induction of apoptosis by shikonin derivatives was also reported in other types of cancer such as medullary thyroid carcinoma cells [6], human gastric cancer cells, and human breast cancer cells [38,39]. To confirm apoptosis induction, immunoblotting and flow cytometric experiments were performed. Caspases are produced as inactive precursors and cleaved into active enzymes when needed. Thereby, many factors, e.g., the induction of double-stranded DNA breaks, can lead to caspase activation. When DNA double-stranded breaks occur, H2AX is phosphorylated as consequence and, subsequently, induces apoptosis. Activated caspases, in turn, cleave other proteins, for example poly (ADP-ribose) polymerase (PARP) [40]. Therefore, protein expression of cleaved PARP and phosphorylated H2AX was investigated. The levels of both proteins were increased by $\mathbf{6}$ as shown in Figure 3A-C. Our results indicate that DNA damage caused by 6 
might be one reason for apoptosis induction. Also, by using FACS experiments, caspase 3 cleavage was seen in MUG-Mel2 and, particularly, in WM9 cells (Figure 3D), confirming the previous results. Furthermore, the combination of $\mathbf{6}$ and the caspase inhibitor Z-VAD-FMK led to a declineof caspase 3 activation again confirming the involvement of caspases.

Since a joint decline of viability and cytotoxicityin the ApoToxGlo ${ }^{\mathrm{TM}}$ assay can be a hint of necrosis induction, the CytoTox $96{ }^{\circledR}$ Non-Radioactive Cytotoxicity Assay (LDH assay) was performed (Figure $4 \mathrm{~A}$ ). The results show that 6 did not significantly damage cell membrane up to $5.0 \mu \mathrm{M}$ and $48 \mathrm{~h}$ incubation. This indicates that necrosis is not involved in the observed cell death.

Previous investigations have also demonstrated that 1 affected the amount of melanoma cells in the S- (SBcl2 and WM35 cells) or G2/M-phase (WM9 and WM164 cells) [8]. Also shikonin led to a cell cycle arrest in different cancer cell lines and immortalized human keratinocytes [41-45]. Therefore, the effects of $\mathbf{6}$ on cell cycle distribution were investigated (Figure 4B-D). However, 6 did not lead to a significant cell cycle arrest, suggesting a different mode of action in these cell lines.

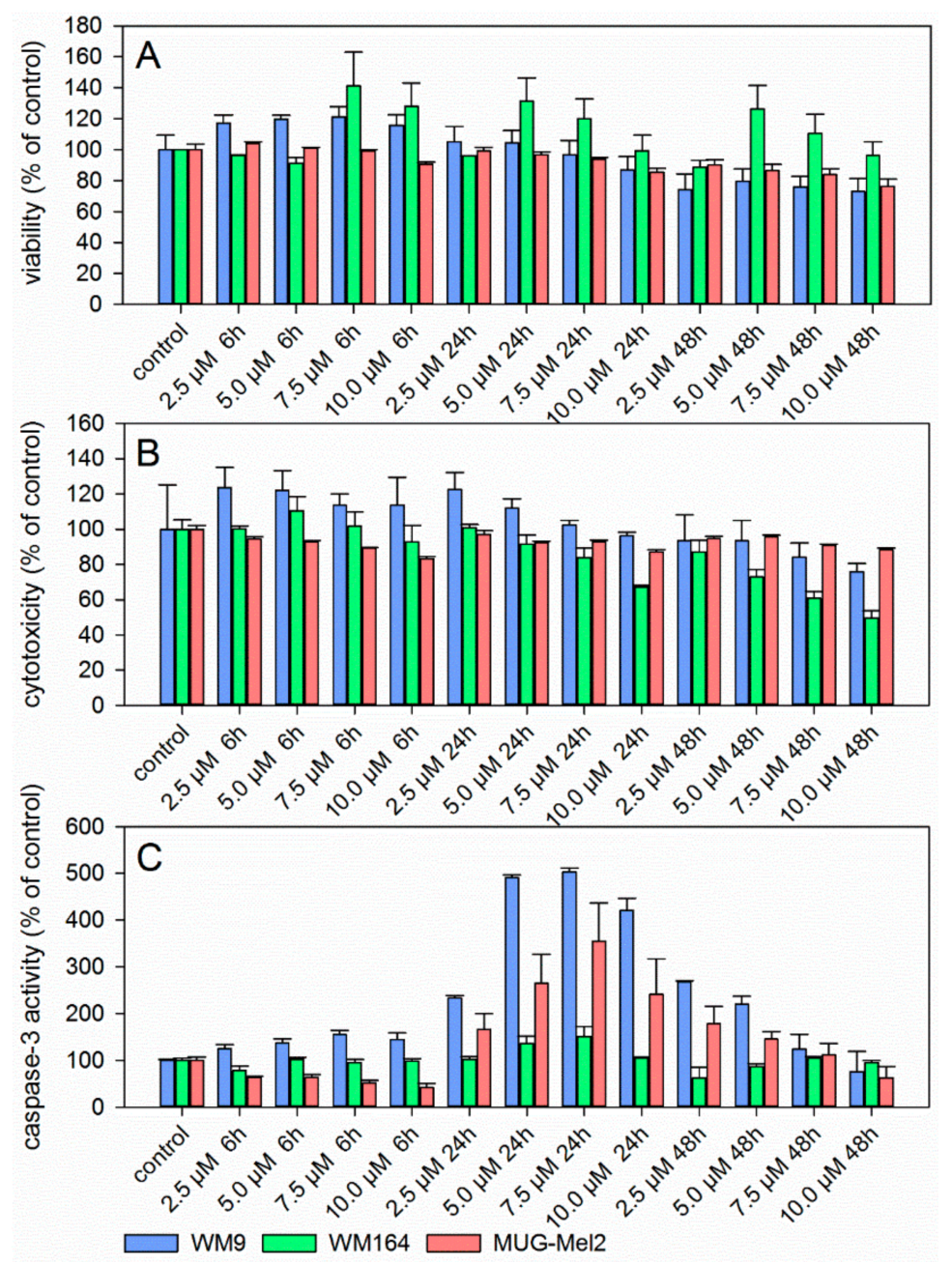

Figure 2. Results of the ApoTox-Glo ${ }^{\mathrm{TM} T r i p l e x}$ assay showing cell viability (A), cytotoxicity (B), and caspase $3 / 7$ activity (C) in different melanoma cells after $6 \mathrm{~h}, 24 \mathrm{~h}$, and $48 \mathrm{~h}$ treatment with 6 (mean \pm SEM, $n=6$ ). Staurosporine $(10.0 \mu \mathrm{M})$ served as positive control for apoptosis induction (caspase activity after $24 \mathrm{~h}$ : WM9: $724.8 \pm 3.8 \%$; WM164: 898.6 $\pm 18.4 \%$, and MUG-Mel2: $637.7 \pm 64.8 \%$ and after 48 h: WM9: $181.1 \pm 4.1 \%$, WM164: $226.6 \pm 22.5 \%$, and MUG-Mel2: $314.1 \pm 41.3 \%$ ). 

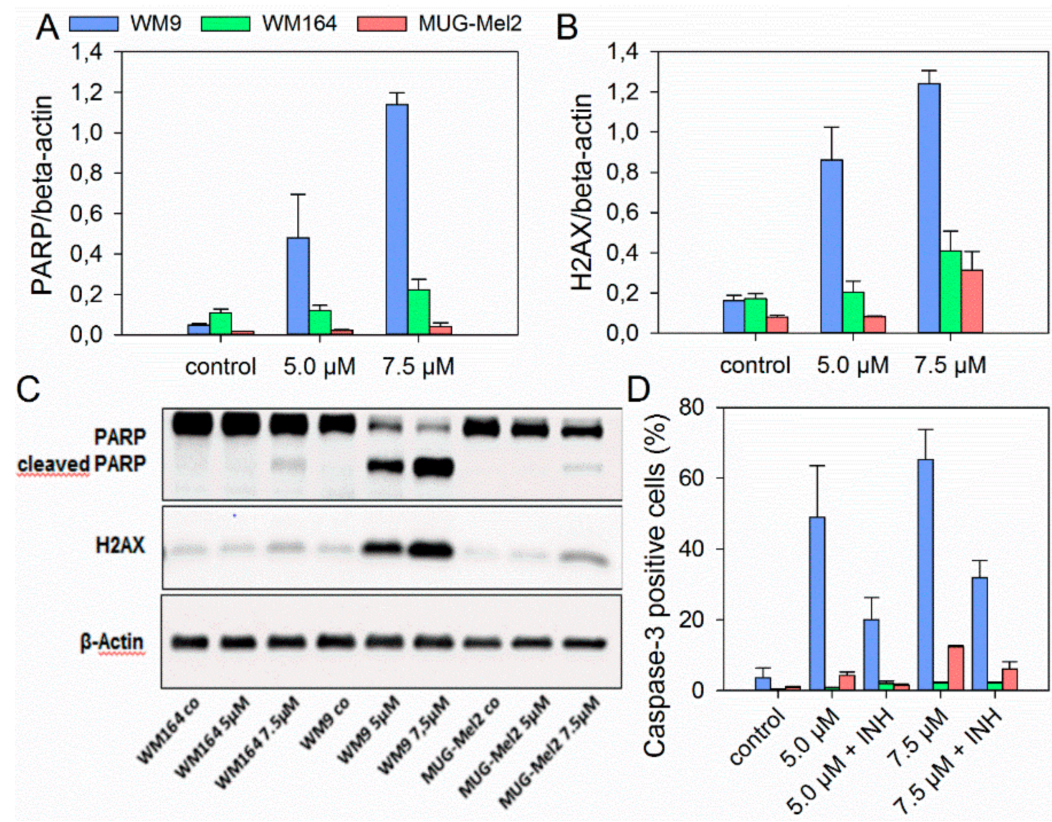

Figure 3. Western blot (A-C) and flow cytometric experiments (D) concerning apoptosis induction in different melanoma cells. (A) Densitometric analysis of the apoptotic marker cleaved PARP and (B) the DNA damage marker phosphorylated H2AX. The effect of 6 on three different melanoma cell lines was evaluated by immunoblotting under control conditions and in the presence of $5.0 \mu \mathrm{M}$ and $7.5 \mu \mathrm{M}$ of 6 for $24 \mathrm{~h}$. Fold change is normalized to controls (mean $\pm \mathrm{SD}, n=3$ ). (C) One representative immunoblot out of three is shown. $\beta$-Actin was used as loading control. (D) Results of cleaved caspase 3 FACS measurements after treatment with $6(5.0$ and $7.5 \mu \mathrm{M})$ and $24 \mathrm{~h}$ incubation with or without caspase 3 inhibitor (INH), which confirmed the results above (mean $\pm \mathrm{SEM}, n=6$ ).
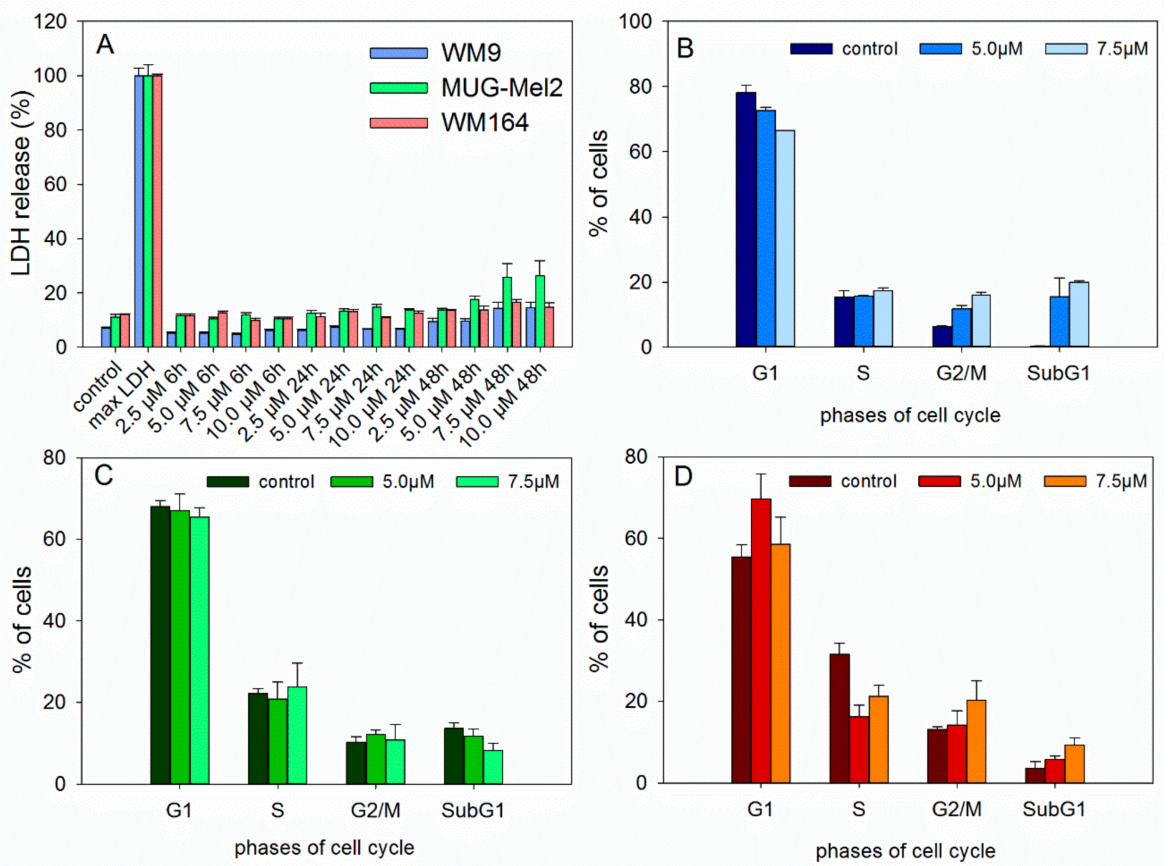

Figure 4. (A) Results of lactate dehydrogenase (LDH) assay showing that 6 caused no significant damage to the cell membrane in different melanoma cells (mean $\pm \mathrm{SEM}, n=6$ ). Maximum LDH release control was used to determine maximal LDH release. (B-D) Treatment of melanoma cells with 6 did not lead to significant changes in the cell cycle distribution (B: WM9, C: MUG-Mel2, and D: WM164 cells, $24 \mathrm{~h}$ of incubation, mean $\pm \mathrm{SEM}, n=3$ ). 


\section{Material and Methods}

\subsection{Chemicals and Synthesis of Derivatives}

\subsubsection{Chemicals}

Shikonin was obtained from Chengdu Biopurify Phytochemicals Ltd. (Chengdu, China). Reagents and solvents were obtained from commercial suppliers. Solvents were dried and purified using standard techniques.

\subsubsection{Synthesis}

Compounds were synthesized as described below and in the Supplementary Material. Derivatives with additional chiral centers in the acyl side chain were not separated into diastereomers. Solvents were of p.a. quality, if not stated otherwise. Analytical thin layer chromatography (TLC) was performed using aluminium foil plates coated with silica $60 \mathrm{~F}_{254}$ (Merck, Darmstadt, Germany). Shikonin derivatives were detected in VIS. Some intermediates were additionally visualized by UV $254 \mathrm{~nm}$ and spraying with molybdatophosphoric acid and subsequent heating. Preparative thin layer chromatography (PTLC) was done on analytical aluminium or plastic foil plates coated with silica 60 $\mathrm{F}_{254}$ (Merck, Darmstadt, Germany) and developed until the solvent front reached $8 \mathrm{~cm}$. For column chromatography (CC), silica gel 60 (63-200 $\mu \mathrm{m}$, Merck, Darmstadt, Germany) was used. Infrared spectra were recorded on a Bruker Alpha Platinum ATR spectrometer (Bruker, Kennewick, WA, USA). ${ }^{1} \mathrm{H}$ and ${ }^{13} \mathrm{C}$-NMR spectra were recorded on Varian $400 \mathrm{MHz}$ UnityINOVA spectrometer (400 and $100 \mathrm{MHz}$, respectively, Varian, Palo Alto, CA, USA) using deuterated chloroform $\left(\mathrm{CDCl}_{3}\right)$ as the solvent and TMS as internal standard. ${ }^{1} \mathrm{H}$ - and ${ }^{13} \mathrm{C}$-resonances are indicated as given in the Table 1. Assignments marked with an asterisk are interchangeable. The purity of all synthesized compounds was verified using NMR and analytical HPLC. The purity exceeded 95\%. Liquid chromatography coupled with electrospray ionization-tandem mass spectrometry (LC-ESI-MS) analyses were carried out on a Dionex Ultimate 3000 UHPLC (Thermo, San José, CA, USA) coupled with a Thermo LTQ XL linear ion trap mass spectrometer equipped with an H-ESI II probe in the negative mode using $500 \mathrm{~nm}$ as acquisition wavelength (source heater temperature, $250{ }^{\circ} \mathrm{C}$, capillary temperature, $200{ }^{\circ} \mathrm{C}$, source voltage, $3.5 \mathrm{kV}$, capillary voltage, $-14 \mathrm{~V}$, sheath gas flow, 50 arbitrary units, auxiliary gas flow, 10 arbitrary units). As stationary phase, a Kinetex C18 column $(2.6 \mu \mathrm{m}, 100 \times 2.10 \mathrm{~mm}$, Phenomenex, Torrance, FL, USA) was used. The mobile phase consisted of water (A) and acetonitrile (B). The gradient was set as follows $0-45 \mathrm{~min}$ : $55-100 \%$ B. Flow rate was $0.2 \mathrm{~mL} / \mathrm{min}$. Column temperature was set at $30{ }^{\circ} \mathrm{C}$.

\subsubsection{General Procedure for the Acylation of Shikonin}

A solution of shikonin in abs. $\mathrm{CH}_{2} \mathrm{Cl}_{2}(0.1 \mathrm{mmol} / 5 \mathrm{~mL})$ was cooled to $0{ }^{\circ} \mathrm{C}$ under argon atmosphere and DCC was added. DMAP was added after stirring for $15 \mathrm{~min}$. After further stirring for $15 \mathrm{~min}$, the corresponding acid was added and stirring was continued for $14 \mathrm{~h}$ to 5 days with slowly warming up to room temperature. After addition of $1 \mathrm{~mL}$ cyclohexane $/ 0.1 \mathrm{mmol}$ shikonin, the mixture was concentrated under reduced pressure at room temperature to approx. $0.5 \mathrm{~mL} / 0.1 \mathrm{mmol}$ shikonin. The mixture was filtered over $3 \mathrm{~mm}$ silica and $2 \mathrm{~mm}$ celite ${ }^{\circledR}$ (eluent: petroleum ether $/ \mathrm{CH}_{2} \mathrm{Cl}_{2}=1: 0$ to 1:2). Product containing fractions were evaporated and submitted to flash CC and/or repeated PTLC (cyclohexane/ $\mathrm{CH}_{2} \mathrm{Cl}_{2}$ mixtures). Due to the rapid decomposition of raw acylshikonin mixtures on evaporation to higher concentrations (c > approx. $0.2 \mathrm{M}$ acylshikonin) and degradation of acylshikonins on prolonged contact with silica, intermediate solutions were not to be concentrated to dryness and all isolation and purification steps had be performed at a good pace.

(R)-1-(1,4-Dihydro-5,8-dihydroxy-1,4-dioxonaphthalen-2-yl)-4-methylpent-3-enyl 2-cyclobutylideneacetate (2): $0.1 \mathrm{mmol}$ Shikonin, $0.20 \mathrm{mmol}$ DCC, $30 \mu \mathrm{mol}$ DMAP, and $0.1 \mathrm{mmol} 2$-cyclobutylideneacetic acid (2a); reaction time 5 days; PTLC on silica (developed twice with cyclohexane $/ \mathrm{CH}_{2} \mathrm{Cl}_{2}=2: 1$ and twice 
with cyclohexane $/ \mathrm{CH}_{2} \mathrm{Cl}_{2}=1: 2$ ) and PTLC on silica with cyclohexane $/ \mathrm{CH}_{2} \mathrm{Cl}_{2}=2: 1$ (three times developed), 2, yield: 3\%. 2: $\mathrm{R}_{\mathrm{f}}=0.31$ (silica, cyclohexane $\left./ \mathrm{CH}_{2} \mathrm{Cl}_{2}=1: 4\right)$ ); IR (ATR): $2957(\mathrm{w}), 2919(\mathrm{~m})$, $\approx 2950(\mathrm{br}), 2851(\mathrm{w}), 1716(\mathrm{~m}), 1668(\mathrm{~m}), 1609(\mathrm{~m}), 1568(\mathrm{~m}), 1454(\mathrm{~m}), 1263(\mathrm{~s}), 1202(\mathrm{~s}), 1170(\mathrm{~s})$, $1108(\mathrm{~m}), 703(\mathrm{w}) \mathrm{cm}^{-1}{ }^{1}{ }^{1} \mathrm{H}-\mathrm{NMR}\left(\mathrm{CDCl}_{3}\right): \delta 1.58\left(\mathrm{~s}, 3 \mathrm{H}, \mathrm{H}-6^{\prime}\right), 1.69\left(\mathrm{~s}, 3 \mathrm{H}, \mathrm{H}-5^{\prime}\right), 2.12$ (quint, $J=7.9 \mathrm{~Hz}$, $\left.2 \mathrm{H}, \mathrm{H}-3^{\prime \prime}\right), 2.49\left(\mathrm{dtm}, J=14.9,7.4 \mathrm{~Hz}, 1 \mathrm{H}, \mathrm{H}-2^{\prime}\right), 2.62\left(\mathrm{dtm}, J=14.9,5.5 \mathrm{~Hz}, 1 \mathrm{H}, \mathrm{H}-2^{\prime}\right), 2.88(\mathrm{t}, J=7.6 \mathrm{~Hz}$, 2H, H-2 $\left.{ }^{\prime \prime}, \mathrm{H}-4^{\prime \prime}\right), 3.14$ (qm, $\left.J=7.7 \mathrm{~Hz}, 2 \mathrm{H}, \mathrm{H}-2^{\prime \prime}, \mathrm{H}-4^{\prime \prime}\right), 5.14\left(\mathrm{tm}, J=7.1 \mathrm{~Hz}, 1 \mathrm{H}, \mathrm{H}-3^{\prime}\right), 5.68$ (quint, $1 \mathrm{H}, J=2.1 \mathrm{~Hz}, \mathrm{H}-\alpha), 6.02\left(\mathrm{dd}, J=7.1,4.4 \mathrm{~Hz}, 1 \mathrm{H}, \mathrm{H}-1^{\prime}\right), 6.96(\mathrm{~d}, J=0.9 \mathrm{~Hz}, 1 \mathrm{H}, \mathrm{H}-3), 7.18(\mathrm{~s}, 2 \mathrm{H}, \mathrm{H}-6$, $\mathrm{H}-7), 12.44$ (s, 1H, C5-OH), 12.59 (s, 1H, C8-OH); ${ }^{13} \mathrm{C}-\mathrm{NMR}\left(\mathrm{CDCl}_{3}\right): \delta 17.6\left(\mathrm{C}-3^{\prime \prime}\right), 18.0\left(\mathrm{C}-6^{\prime}\right), 25.8$ $\left.\left(\mathrm{C}-5^{\prime}\right), 32.4\left(\mathrm{C}-2^{\prime \prime *}\right), 32.9\left(\mathrm{C}-2^{\prime}\right), 34.1 \mathrm{C}-4^{\prime \prime *}\right), 69.0\left(\mathrm{C}-1^{\prime}\right), 111.6(\mathrm{C}-4 \mathrm{a}, \mathrm{C}-\alpha), 111.8(\mathrm{C}-8 \mathrm{a}), 118.1\left(\mathrm{C}-3^{\prime}\right), 131.6$ (C-3), 132.5 (C-6, C-7), 135.9 (C-4'), 148.9 (C-2), 165.1 (COO), 166.2 (C-5), 166.8 (C-8), 169.8 (C-1" ), 177.4 (C-1), 179.0 (C-4); $\mathrm{MS}_{\left(\mathrm{ESI}^{-}\right)} \mathrm{m} / z(\%): 819$ (16) [2(M - H) + Cl + Na $]^{-}, 785(37)[2(\mathrm{M}-\mathrm{H})+\mathrm{Na}]^{-}, 417$ and $415(14)[\mathrm{M}-2 \mathrm{H}+\mathrm{Cl}]^{-}, 382.11(100)\left[\mathrm{M}^{-}\right.$; $381.21(53)[\mathrm{M}-\mathrm{H}]^{-}, 137(44) ;[\mathrm{M}]^{-}$calculated for $\mathrm{C}_{22} \mathrm{H}_{22} \mathrm{O}_{6}: 382.1416$.

(R)-1-(1,4-Dihydro-5,8-dihydroxy-1,4-dioxonaphthalen-2-yl)-4-methylpent-3-enyl 2-cyclopentylideneacetate (3): $0.1 \mathrm{mmol}$ Shikonin, $0.20 \mathrm{mmol}$ DCC, $25 \mu \mathrm{mol}$ DMAP, and $0.11 \mathrm{mmol}$ 2-cyclopentylideneacetic acid (3a); reaction time $16 \mathrm{~h}$; PTLC on silica (developed twice with cyclohexane $/ \mathrm{CH}_{2} \mathrm{Cl}_{2}=2: 1$ and twice with cyclohexane $/ \mathrm{CH}_{2} \mathrm{Cl}_{2}=1: 2$ ) and PTLC on silica with cyclohexane $/ \mathrm{CH}_{2} \mathrm{Cl}_{2}=2: 1$ (four times developed),

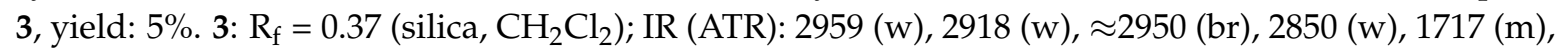
1648 (m), 1609 (vs), 1569 (m), 1453 (m), 1230 (m), 1188 (vs), 1114 (s) cm ${ }^{-1},{ }^{1} \mathrm{H}-\mathrm{NMR}\left(\mathrm{CDCl}_{3}\right): 1.58$ (s, $\left.3 \mathrm{H}, \mathrm{H}-6^{\prime}\right), 1.68\left(\mathrm{~m}, 2 \mathrm{H}, \mathrm{H}-4^{\prime \prime}\right), 1.69\left(\mathrm{~s}, 3 \mathrm{H}, \mathrm{H}-5^{\prime}\right), 1.75\left(\mathrm{~m}, 2 \mathrm{H}, \mathrm{H}-3^{\prime \prime}\right), 2.48\left(\mathrm{~m}, 3 \mathrm{H}, \mathrm{H}-2^{\prime}\right.$ and H-2 $\left.{ }^{\prime \prime}\right), 2.63$ $\left(\mathrm{dtm}, J=15.3,5.4 \mathrm{~Hz}, 1 \mathrm{H}, \mathrm{H}-2^{\prime}\right), 2.75\left(\mathrm{~m}, 2 \mathrm{H}, \mathrm{H}-5^{\prime \prime}\right), 5.15\left(\mathrm{tm}, J=7.2 \mathrm{~Hz}, 1 \mathrm{H}, \mathrm{H}-3^{\prime}\right), 5.90$ (quint, $1 \mathrm{H}$, $J=1.9 \mathrm{~Hz}, \mathrm{H}-\alpha), 6.02\left(\mathrm{dd}, J=7.4,4.7 \mathrm{~Hz}, 1 \mathrm{H}, \mathrm{H}-1^{\prime}\right), 6.97(\mathrm{~d}, J=0.8 \mathrm{~Hz}, 1 \mathrm{H}, \mathrm{H}-3), 7.18(\mathrm{~s}, 2 \mathrm{H}, \mathrm{H}-6$ and $\mathrm{H}-7), 12.43$ (s, 1H, C5-OH), 12.60 (s, 1H, C8-OH); ${ }^{13} \mathrm{C}-\mathrm{NMR}\left(\mathrm{CDCl}_{3}\right): \delta 18.0\left(\mathrm{C}-6^{\prime}\right), 25.5\left(\mathrm{C}-4^{\prime \prime}\right), 25.8$ (C-5'), $26.4\left(\mathrm{C}-3^{\prime \prime}\right), 32.9,33.0\left(\mathrm{C}-2^{\prime}, \mathrm{C}-2^{\prime \prime}\right), 36.2\left(\mathrm{C}-5^{\prime \prime}\right), 68.7$ (C-1'), 110.9 (C- $\left.\alpha\right), 111.7$ (C-4a), 111.8 (C-8a), 118.1 (C-3'), 131.6 (C-3), 132.4 (C-7), 133.5 (C-6), 135.8 (C-4'), 149.2 (C-2), 165.5 (COO), 166.1 (C-5), 166.7 (C-8), $171.5\left(\mathrm{C}-1^{\prime \prime}\right), 177.7$ (C-1), $\left.179.1(\mathrm{C}-4) ; \mathrm{MS}_{\left(\mathrm{ESI}^{-}\right)}\right) \mathrm{m} / \mathrm{z}(\%): 813(10)[2(\mathrm{M}-\mathrm{H})+\mathrm{Na}]^{-}, 395.30$ (100) $[\mathrm{M}-\mathrm{H}]^{-} ;[\mathrm{M}-\mathrm{H}]^{-}$calculated for $\mathrm{C}_{23} \mathrm{H}_{24} \mathrm{O}_{6}$ : 395.1495 .

(R)-1-(1,4-Dihydro-5,8-dihydroxy-1,4-dioxonaphthalen-2-yl)-4-methylpent-3-enyl 2-cyclohexylideneacetate (4): $0.1 \mathrm{mmol}$ Shikonin, $0.20 \mathrm{mmol} \mathrm{DCC}, 25 \mu \mathrm{mol}$ DMAP, and $0.11 \mathrm{mmol}$ 2-cyclohexylideneacetic acid (4a); reaction time $16 \mathrm{~h}$; Flash-CC on silica (3 g) with petroleum ether $/ \mathrm{CH}_{2} \mathrm{Cl}_{2}=0: 1$ to 1:0) and PTLC on silica each developed twice with cyclohexane $/ \mathrm{CH}_{2} \mathrm{Cl}_{2}=2: 1$ and twice with cyclohexane $\left./ \mathrm{CH}_{2} \mathrm{Cl}_{2}=1: 2\right)$; 4, yield: 13\%. 4: $\mathrm{R}_{\mathrm{f}}=0.31$ (silica, $\mathrm{CH}_{2} \mathrm{Cl}_{2}$ ); IR (ATR): 2919 (m), $\approx 2950$ (br) (OH), $2851(\mathrm{w}), 1720(\mathrm{~m})$ $(\mathrm{C}=\mathrm{O}), 1643(\mathrm{~m}), 1610(\mathrm{~s}), 1570(\mathrm{~m}), 1451(\mathrm{~m}), 1266(\mathrm{~m}), 1233(\mathrm{~m}), 1201(\mathrm{~s})(\mathrm{COC}), 1147(\mathrm{~s}), 777(\mathrm{w}) \mathrm{cm}^{-1}$; ${ }^{1} \mathrm{H}-\mathrm{NMR}\left(\mathrm{CDCl}_{3}\right): 1.58$ (s, 3H, H-6'), 1.59-1.70 (m, 6H, H-3" $\left.{ }^{\prime \prime} \mathrm{H}-4^{\prime \prime}, \mathrm{H}-5^{\prime \prime}\right), 1.69$ (s, 3H, H-5'), 1.75 (m, $\left.2 \mathrm{H}, \mathrm{H}-3^{\prime \prime}\right), 2.23\left(\mathrm{t}, J=6.5 \mathrm{~Hz}, 2 \mathrm{H}, \mathrm{H}-2^{\prime \prime}\right), 2.48\left(\mathrm{dt}, J=15.0,7.3 \mathrm{~Hz}, 1 \mathrm{H}, \mathrm{H}-2^{\prime}\right), 2.62(\mathrm{dtm}, J=15.2,5.4 \mathrm{~Hz}$, $\left.1 \mathrm{H}, \mathrm{H}-2^{\prime}\right), 2.75\left(\mathrm{t}, J=5.5 \mathrm{~Hz}, 2 \mathrm{H}, \mathrm{H}-6^{\prime \prime}\right), 5.15\left(\mathrm{tm}, J=7.2 \mathrm{~Hz}, 1 \mathrm{H}, \mathrm{H}-3^{\prime}\right), 5.70(\mathrm{~s}, 1 \mathrm{H}, \mathrm{H}-\alpha), 6.02(\mathrm{dd}, J=7.4$, $\left.4.7 \mathrm{~Hz}, 1 \mathrm{H}, \mathrm{H}-1^{\prime}\right), 6.98$ (d, J = 0.8 Hz, 1H, H-3), 7.18 (s, 2H, H-6 and H-7), 12.44 (s, 1H, C5-OH), 12.60 $(\mathrm{s}, 1 \mathrm{H}, \mathrm{C} 8-\mathrm{OH}) ;{ }^{13} \mathrm{C}-\mathrm{NMR}\left(\mathrm{CDCl}_{3}\right): \delta 18.0\left(\mathrm{C}-6^{\prime}\right), 25.8\left(\mathrm{C}-5^{\prime}\right), 26.2\left(\mathrm{C}-4^{\prime \prime}\right), 27.8\left(\mathrm{C}-5^{\prime \prime}\right), 28.6\left(\mathrm{C}-3^{\prime \prime}\right), 30.0$ (C-6 $\left.{ }^{\prime \prime}\right), 32.9$ (C-2'), $38.1\left(\mathrm{C}-2^{\prime \prime}\right), 68.6$ (C-1'), 111.6 (C-4a), 111.9 (C-8a), 112.1 (C- $\left.\alpha\right), 118.0\left(\mathrm{C}-3^{\prime}\right), 131.7$ (C-3), 132.4 (C-7), 132.6 (C-6), 135.9 (C-4'), 149.1 (C-2), 165.4 (COO), $166.0\left(\mathrm{C}-1^{\prime \prime}\right), 166.3(\mathrm{C}-5), 166.8$

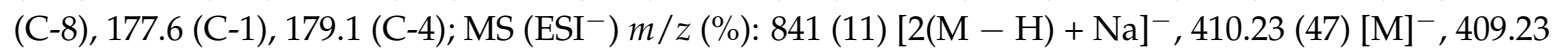
(100) $[\mathrm{M}-\mathrm{H}]^{-} ;[\mathrm{M}]^{-}$calculated for $\mathrm{C}_{24} \mathrm{H}_{26} \mathrm{O}_{6}: 410.1729$.

(R)-1-(1,4-Dihydro-5,8-dihydroxy-1,4-dioxonaphthalen-2-yl)-4-methylpent-3-enyl 2-cycloheptylideneacetate (5): $0.1 \mathrm{mmol}$ Shikonin, $0.20 \mathrm{mmol}$ DCC, $25 \mu \mathrm{mol}$ DMAP, and $0.11 \mathrm{mmol}$ 2-cycloheptylideneacetic acid (5a); reaction time $16 \mathrm{~h}$; PTLC on silica (developed twice with cyclohexane $/ \mathrm{CH}_{2} \mathrm{Cl}_{2}=2: 1$ and twice with cyclohexane $/ \mathrm{CH}_{2} \mathrm{Cl}_{2}=1: 2$ ) and PTLC on silica with cyclohexane $/ \mathrm{CH}_{2} \mathrm{Cl}_{2}=2: 1$ (four times developed),

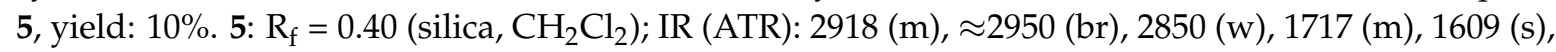
$1569(\mathrm{~m}), 1560(\mathrm{~m}), 1453(\mathrm{~m}), 1201(\mathrm{~m}), 1136$ (s), $779(\mathrm{w}) \mathrm{cm}^{-1},{ }^{1} \mathrm{H}-\mathrm{NMR}\left(\mathrm{CDCl}_{3}\right):$ 1.52-1.55 (m, 2H, $\left.\mathrm{H}-4^{\prime \prime}, \mathrm{H}-5^{\prime \prime}\right), 1.55\left(\mathrm{~s}, 3 \mathrm{H}, \mathrm{H}-6^{\prime}\right), 1.62-1.69\left(\mathrm{~m}, 2 \mathrm{H}, \mathrm{H}-3^{\prime \prime}, \mathrm{H}-6^{\prime \prime}\right), 1.69\left(\mathrm{~s}, 3 \mathrm{H}, \mathrm{H}-5^{\prime}\right), 2.42\left(\mathrm{~m}, 2 \mathrm{H}, \mathrm{H}-2^{\prime \prime}\right)$, 
$2.49\left(\mathrm{dtm}, J=14.8,7.3 \mathrm{~Hz}, 1 \mathrm{H}, \mathrm{H}-2^{\prime}\right), 2.61\left(\mathrm{dtm}, J=14.9,5.0 \mathrm{~Hz}, 1 \mathrm{H}, \mathrm{H}-2^{\prime}\right), 2.85\left(\mathrm{~m}, 2 \mathrm{H}, \mathrm{H}-7^{\prime \prime}\right), 5.15$ $\left(\mathrm{tm}, J=7.4 \mathrm{~Hz}, 1 \mathrm{H}, \mathrm{H}-3^{\prime}\right), 5.77(\mathrm{~s}, 1 \mathrm{H}, \mathrm{H}-\alpha), 6.01\left(\mathrm{ddd}, J=7.2,4.6,0.8 \mathrm{~Hz}, 1 \mathrm{H}, \mathrm{H}-1^{\prime}\right), 6.98(\mathrm{~d}, J=0.8 \mathrm{~Hz}$, 1H, H-3), 7.18 (s, 2H, H-6, H-7), 12.44 (s, 1H, C5-OH), 12.60 (s, 1H, C8-OH); ${ }^{13} \mathrm{C}-\mathrm{NMR}\left(\mathrm{CDCl}_{3}\right): \delta 18.0$ $\left(\mathrm{C}-6^{\prime}\right), 25.8\left(\mathrm{C}-5^{\prime}\right), 26.6\left(\mathrm{C}-6^{\prime \prime}\right), 27.9\left(\mathrm{C}-3^{\prime \prime}\right), 29.0\left(\mathrm{C}-4^{\prime \prime}\right), 29.8\left(\mathrm{C}-5^{\prime \prime}\right), 32.3\left(\mathrm{C}-7^{\prime \prime}\right), 33.0\left(\mathrm{C}-2^{\prime}\right), 39.2\left(\mathrm{C}-2^{\prime \prime}\right)$, $68.5\left(\mathrm{C}-1^{\prime}\right), 111.6(\mathrm{C}-4 \mathrm{a}), 111.9$ (C-8a), 114.7 (C- $\left.\alpha\right), 118.1\left(\mathrm{C}-3^{\prime}\right), 131.7$ (C-3), 132.4 (C-7), 133.5 (C-6), 135.8 (C-4'), 149.2 (C-2), 165.2 (COO), 166.1 (C-5), 166.7 (C-8), $169.2\left(\right.$ C-1 $\left.^{\prime \prime}\right), 177.7$ (C-1), $179.2(\mathrm{C}-4)$; MS (ESI $\left.{ }^{-}\right)$ $m / z(\%): 869(15)\left[2(\mathrm{M}-\mathrm{H})+\mathrm{Na}^{-}, 424.25(45)[\mathrm{M}]^{-}, 423.22(100)[\mathrm{M}-\mathrm{H}]^{-} 159 \text { (31), } 137 \text { (39); [M] }\right]^{-}$ calculated for $\mathrm{C}_{25} \mathrm{H}_{28} \mathrm{O}_{6}$ : 424.1886 .

(R)-1-(1,4-Dihydro-5,8-dihydroxy-1,4-dioxonaphthalen-2-yl)-4-methylpent-3-enyl cyclopropylacetate (6): $0.2 \mathrm{mmol}$ Shikonin, $0.4 \mathrm{mmol}$ DCC, $80 \mu \mathrm{mol}$ DMAP, and $0.25 \mathrm{mmol}$ cyclopropylacetic acid (6a); reaction time $16 \mathrm{~h}$; $\mathrm{CC}$ on silica $(7 \mathrm{~g})$ with cyclohexane $/ \mathrm{CH}_{2} \mathrm{Cl}_{2}=2: 1$ to $1: 4 ; 6$, yield $26 \% .6: \mathrm{R}_{\mathrm{f}}=0.29$

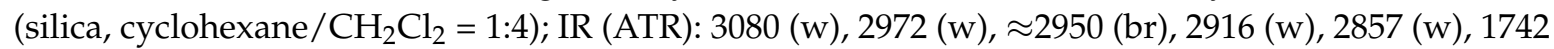
(s), $1610(\mathrm{~s}), 1570(\mathrm{~m}), 1454(\mathrm{~m}), 1231$ (m), $1204(\mathrm{~s}), 784(\mathrm{~m}) \mathrm{cm}^{-1} ;{ }^{1} \mathrm{H}-\mathrm{NMR}\left(\mathrm{CDCl}_{3}\right): 0.17-0.24(\mathrm{~m}, 2 \mathrm{H}$, $\left.\mathrm{H}-2^{\prime \prime}, \mathrm{H}-3^{\prime \prime}\right), 0.56-0.63$ (m, 2H, H-2", $\left.\mathrm{H}-3^{\prime \prime}\right), 1.02-1.13\left(\mathrm{~m}, 1 \mathrm{H}, \mathrm{H}-\mathrm{1}^{\prime \prime}\right), 1.58$ (s, 3H, H-6'), 1.69 (s, 3H, $\left.\mathrm{H}-5^{\prime}\right), 2.23-2.37(\mathrm{~m}, 2 \mathrm{H}, \mathrm{H}-\alpha), 2.49\left(\mathrm{dtm}, J=15.0,7.5 \mathrm{~Hz}, 1 \mathrm{H}, \mathrm{H}-2^{\prime}\right), 2.63\left(\mathrm{dtm}, J=15.0,5.5 \mathrm{~Hz}, 1 \mathrm{H}, \mathrm{H}-2^{\prime}\right)$, $5.14\left(\mathrm{tm}, J=7.1 \mathrm{~Hz}, 1 \mathrm{H}, \mathrm{H}-3^{\prime}\right), 6.05\left(\mathrm{ddd}, J=7.3,4.5,1.0 \mathrm{~Hz}, 1 \mathrm{H}, \mathrm{H}-1^{\prime}\right), 7.01(\mathrm{~d}, J=1.0 \mathrm{~Hz}, 1 \mathrm{H}, \mathrm{H}-3)$, 7.19 (s, 2H, H-6, H-7), 12.43 (s, 1H, C5-OH), 12.59 (s, 1H, C8-OH); ${ }^{13} \mathrm{C}-\mathrm{NMR}\left(\mathrm{CDCl}_{3}\right): \delta 4.4,4.5\left(\mathrm{C}-2^{\prime \prime}\right.$, C-3" $\left.{ }^{\prime \prime}\right), 7.0\left(\mathrm{C}-1^{\prime \prime}\right), 18.0\left(\mathrm{C}-6^{\prime}\right), 25.8\left(\mathrm{C}-5^{\prime}\right), 32.9\left(\mathrm{C}-2^{\prime}\right), 39.5(\mathrm{C}-\alpha), 69.4\left(\mathrm{C}-1^{\prime}\right), 111.6(\mathrm{C}-4 \mathrm{a}), 111.8$ (C-8a), 117.8 (C-3'), 131.5 (C-3), 132.7 (C-7), 132.8 (C-6), 136.0 (C-4'), 148.4 (C-2), 166.8 (C-5), 167.4 (C-8), 172.0 (COO), $176.8(\mathrm{C}-1), 178.3(\mathrm{C}-4) ; \mathrm{MS}_{\left(\mathrm{ESI}^{-}\right)} \mathrm{m} / z(\%): 1165$ (5) $[3 \mathrm{M}-3 \mathrm{H}+\mathrm{Na}+\mathrm{K}]^{-}, 1147$ (7) [3M $-2 \mathrm{H}+$ $\mathrm{K}]^{-}, 1131(11)[3 \mathrm{M}-2 \mathrm{H}+\mathrm{Na}]^{-}, 761(1)[2(\mathrm{M}-\mathrm{H})+\mathrm{Na}]^{-}, 637(2)[2 \mathrm{M}-3 \mathrm{H}-\mathrm{RCOOH}]^{-}, 370.22$ (32) $[\mathrm{M}]^{-}, 369.25(100)[\mathrm{M}-\mathrm{H}]^{-} ;[\mathrm{M}]^{-}$calculated for $\mathrm{C}_{21} \mathrm{H}_{22} \mathrm{O}_{6}: 370.1416$.

(R)-1-(1,4-Dihydro-5,8-dihydroxy-1,4-dioxonaphthalen-2-yl)-4-methylpent-3-enyl cyclobutylacetate (7): $50 \mu \mathrm{mol}$ Shikonin, $0.15 \mathrm{mmol}$ DCC, $30 \mu \mathrm{mol}$ DMAP, and $53 \mu \mathrm{mol}$ cyclobutylacetic acid (7a); reaction time $16 \mathrm{~h}$; PTLC on silica (developed twice with cyclohexane $/ \mathrm{CH}_{2} \mathrm{Cl}_{2}=2: 1$ and one time with cyclohexane $/ \mathrm{CH}_{2} \mathrm{Cl}_{2}=1: 2$ ) and an additional PTLC on silica (developed twice with cyclohexane $/ \mathrm{CH}_{2} \mathrm{Cl}_{2}=2: 1$ ); 7 , yield: $21 \% .7: \mathrm{R}_{\mathrm{f}}=0.21$ (silica, cyclohexane $/ \mathrm{CH}_{2} \mathrm{Cl}_{2}=1: 4$ ); IR (ATR): $2959(\mathrm{w}), 2918(\mathrm{~m}), \approx 2950(\mathrm{br}), 2851(\mathrm{w}), 1737(\mathrm{~m}), 1609(\mathrm{~s}), 1568(\mathrm{~m}), 1453(\mathrm{~m}), 1264(\mathrm{~m}), 1229(\mathrm{~m})$, $1202(\mathrm{~s}), 1158(\mathrm{~m}), 777(\mathrm{w}) \mathrm{cm}^{-1},{ }^{1} \mathrm{H}-\mathrm{NMR}\left(\mathrm{CDCl}_{3}\right): 1.58\left(\mathrm{~s}, 3 \mathrm{H}, \mathrm{H}-6^{\prime}\right), 1.69\left(\mathrm{~s}, 3 \mathrm{H}, \mathrm{H}-5^{\prime}\right), 1.70-1.78(\mathrm{~m}$, $2 \mathrm{H}$, trans $\mathrm{H}-2^{\prime \prime}$, trans $\left.\mathrm{H}-4^{\prime \prime}\right), 1.81-1.97\left(\mathrm{~m}, 2 \mathrm{H}, \mathrm{H}-3^{\prime \prime}\right), 2.09-2.20\left(\mathrm{~m}, 2 \mathrm{H}\right.$, cis $\mathrm{H}-2^{\prime \prime}$, cis H- $\left.4^{\prime \prime}\right), 2.46(\mathrm{dtm}$, $\left.J=15.0,7.5 \mathrm{~Hz}, 1 \mathrm{H}, \mathrm{H}-2^{\prime}\right), 2.49(\mathrm{~d}, J=7.5 \mathrm{~Hz}, 2 \mathrm{H}, \mathrm{H}-\alpha), 2.60\left(\mathrm{dtm}, J=14.7,5.9 \mathrm{~Hz}, 1 \mathrm{H}, \mathrm{H}-2^{\prime}\right), 2.71$ (quint, $\left.J=7.8 \mathrm{~Hz}, 1 \mathrm{H}, \mathrm{H}-1^{\prime \prime}\right), 5.11\left(\mathrm{tm}, J=7.3 \mathrm{~Hz}, 1 \mathrm{H}, \mathrm{H}-3^{\prime}\right), 6.00\left(\mathrm{ddd}, J=7.7,4.2,0.9 \mathrm{~Hz}, 1 \mathrm{H}, \mathrm{H}-1^{\prime}\right), 6.96(\mathrm{~d}$, $J=1.0 \mathrm{~Hz}, 1 \mathrm{H}, \mathrm{H}-3), 7.18$ (s, 2H, H-6, H-7), 12.42 (s, 1H, C5-OH), 12.57 (s, 1H, C8-OH); ${ }^{13} \mathrm{C}-\mathrm{NMR}$ $\left(\mathrm{CDCl}_{3}\right): \delta 18.0\left(\mathrm{C}-6^{\prime}\right), 18.5\left(\mathrm{C}-3^{\prime \prime}\right), 25.8\left(\mathrm{C}-5^{\prime}\right), 28.2,28.3\left(\mathrm{C}-2^{\prime \prime}, \mathrm{C}-4^{\prime \prime}\right), 32.2\left(\mathrm{C}-1^{\prime \prime}\right), 32.9\left(\mathrm{C}-2^{\prime}\right), 41.2(\mathrm{C}-\alpha)$, 69.2 (C-1'), 111.6 (C-4a), 111.8 (C-8a), 117.8 (C-3'), 131.4 (C-3), 132.7 (C-7), 132.9 (C-6), 136.0 (C-4'), 148.5 (C-2), 166.9 (C-5), 167.4 (C-8), 171.5 (COO), 176.8 (C-1), 178.3 (C-4); $\mathrm{MS}_{\left(\mathrm{ESI}^{-}\right)} \mathrm{m} / z$ (\%): 789.37 (8) [2(M $-\mathrm{H})+\mathrm{Na}]^{-}, 384.21[\mathrm{M}]^{-}(52), 383.26(100)[\mathrm{M}-\mathrm{H}]^{-} ;[\mathrm{M}]^{-}$calculated for $\mathrm{C}_{22} \mathrm{H}_{24} \mathrm{O}_{6}: 384.1573$.

(R)-1-(1,4-Dihydro-5,8-dihydroxy-1,4-dioxonaphthalen-2-yl)-4-methylpent-3-enyl cyclopentylacetate (8): $0.1 \mathrm{mmol}$ Shikonin, $0.15 \mathrm{mmol}$ DCC, $25 \mu \mathrm{mol}$ DMAP, and $0.1 \mathrm{mmol}$ cyclopentylacetic acid (8a); reaction time $17 \mathrm{~h}$; $\mathrm{CC}$ on silica $(7 \mathrm{~g})$ with cyclohexane $/ \mathrm{CH}_{2} \mathrm{Cl}_{2}=2: 5$ and PTLC on silica with cyclohexane $/ \mathrm{CH}_{2} \mathrm{Cl}_{2}=2: 5$ (three times developed); 8, yield $10 \% .8: \quad \mathrm{R}_{\mathrm{f}}=0.26$ (silica, cyclohexane $/ \mathrm{CH}_{2} \mathrm{Cl}_{2}$ = 1:4); IR (ATR): 2951 (m, br), $2866(\mathrm{w}), 1738$ (s), 1608 (s), $1569(\mathrm{~m}), 1452(\mathrm{~m}), 1230$ (s), $1200(\mathrm{~s}), 1111(\mathrm{~s}), 777(\mathrm{~m}) \mathrm{cm}^{-1},{ }^{1} \mathrm{H}-\mathrm{NMR}\left(\mathrm{CDCl}_{3}\right): 1.12-1.23\left(\mathrm{~m}, 2 \mathrm{H}, \mathrm{H}-2^{\prime \prime}, \mathrm{H}-5^{\prime \prime}\right), 1.58$ (s, 3H, H-6 $)$, 1.52-1.68 (m, 4H, H-3", $\left.\mathrm{H}-4^{\prime \prime}\right), 1.69$ (s, 3H, H-5'), 1.78-1.88 (m, 2H, H-2 $\left.{ }^{\prime \prime}, \mathrm{H}-5^{\prime \prime}\right), 2.25$ (sept, $J=7.7 \mathrm{~Hz}$, $\left.1 \mathrm{H}, \mathrm{H}-1^{\prime \prime}\right), 2.37-2.43(\mathrm{~m}, 2 \mathrm{H}, \mathrm{H}-\alpha), 2.47\left(\mathrm{dtm}, J=15.1,7.5 \mathrm{~Hz}, 1 \mathrm{H}, \mathrm{H}-2^{\prime}\right), 2.61(\mathrm{dtm}, J=15.0,5.7 \mathrm{~Hz}$, $\left.1 \mathrm{H}, \mathrm{H}-2^{\prime}\right), 5.13\left(\mathrm{tm}, J=7.3 \mathrm{~Hz}, 1 \mathrm{H}, \mathrm{H}-3^{\prime}\right), 6.03\left(\mathrm{ddd}, J=7.3,4.4,0.8 \mathrm{~Hz}, 1 \mathrm{H}, \mathrm{H}-1^{\prime}\right), 6.99(\mathrm{~d}, J=1.0 \mathrm{~Hz}$, $1 \mathrm{H}, \mathrm{H}-3), 7.19$ (s, 2H, H-6, H-7), 12.43 (s, 1H, C5-OH), 12.59 (s, 1H, C8-OH); ${ }^{13} \mathrm{C}-\mathrm{NMR}\left(\mathrm{CDCl}_{3}\right): \delta 18.0$ $\left(\mathrm{C}-6^{\prime}\right), 25.0\left(\mathrm{C}-3^{\prime \prime}, \mathrm{C}-4^{\prime \prime}\right), 25.8\left(\mathrm{C}-5^{\prime}\right), 32.4,32.5\left(\mathrm{C}-2^{\prime \prime}, \mathrm{C}-5^{\prime \prime}\right), 33.0\left(\mathrm{C}-2^{\prime}\right), 36.5\left(\mathrm{C}-1^{\prime \prime}\right), 40.4(\mathrm{C}-\alpha), 69.2$ (C-1'), 111.6 (C-4a), 111.8 (C-8a), 117.9 (C-3'), 131.5 (C-3), 132.7 (C-7), 132.8 (C-6), 136.0 (C-4'), 148.5 
(C-2), 166.8 (C-5), 167.4 (C-8), 172.1 (COO), 176.8 (C-1), 178.3 (C-4); MS (ESI-) $m / z$ (\%): 1231 (9) [3M $2 \mathrm{H}+\mathrm{K}^{-}, 1215(8)[3 \mathrm{M}-2 \mathrm{H}+\mathrm{Na}]^{-}, 398.23(34)[\mathrm{M}]^{-}, 397.30(100)[\mathrm{M}-\mathrm{H}]^{-}$; $[\mathrm{M}]^{-}$calculated for $\mathrm{C}_{23} \mathrm{H}_{26} \mathrm{O}_{6}: 398.1729$.

(R)-1-(1,4-Dihydro-5,8-dihydroxy-1,4-dioxonaphthalen-2-yl)-4-methylpent-3-enyl cyclohexylacetate (9): $50 \mu \mathrm{mol}$ Shikonin, $0.15 \mathrm{mmol}$ DCC, $30 \mu \mathrm{mol}$ DMAP, and $53 \mu \mathrm{mol}$ cyclohexylacetic acid (9a); reaction time $19 \mathrm{~h}$; flash CC on silica (8 g) with cyclohexane $/ \mathrm{CH}_{2} \mathrm{Cl}_{2}=2: 1$ to cyclohexane $\left./ \mathrm{CH}_{2} \mathrm{Cl}_{2}=0: 1\right)$ and an additional PTLC on silica (developed three times with cyclohexane $/ \mathrm{CH}_{2} \mathrm{Cl}_{2}=2: 1$ and one time with cyclohexane $/ \mathrm{CH}_{2} \mathrm{Cl}_{2}=1: 2$ ); 9, yield: $36 \%$. 9: $\mathrm{R}_{\mathrm{f}}=0.21$ (silica, cyclohexane $/ \mathrm{CH}_{2} \mathrm{Cl}_{2}=1: 4$ ); IR (ATR): 2920 (s), ₹2950 (br), 2850 (m), 1738 (s), 1610 (s), 1570 (m), 1450 (s), 1230 (s), 1204 (s), 1160 (m), $1111(\mathrm{~m}), 782(\mathrm{w}) \mathrm{cm}^{-1},{ }^{1} \mathrm{H}-\mathrm{NMR}\left(\mathrm{CDCl}_{3}\right)$ : 0.92-1.05 (m, 2H, H-2" ax, H-6" $\left.{ }^{\prime \prime} \mathrm{ax}\right), 1.09-1.22(\mathrm{~m}, 1 \mathrm{H}$, H-4" ax), 1.21-1.33 (m, 2H, H-3" ax, H-5"'ax), 1.59 (s, 3H, H-6'), 1.62-1.76 (m, 5H, H-2"eq, H-3" eq, $\mathrm{H}-4^{\prime \prime}$ eq, $\mathrm{H}-5^{\prime \prime}$ eq, $\mathrm{H}-6^{\prime \prime}$ eq), 1.76-1.86 (m, 1H, H-1"), 2.24 (dd, 12.4, $\left.4.7 \mathrm{~Hz}, 1 \mathrm{H}, \mathrm{H}-\alpha\right), 2.29$ (dd, 12.4, $5.0 \mathrm{~Hz}, 1 \mathrm{H}, \mathrm{H}-\alpha), 2.47\left(\mathrm{dtm}, J=14.8,7.5 \mathrm{~Hz}, 1 \mathrm{H}, \mathrm{H}-2^{\prime}\right), 2.61\left(\mathrm{dtm}, J=15.1,5.7 \mathrm{~Hz}, 1 \mathrm{H}, \mathrm{H}-2^{\prime}\right), 5.12(\mathrm{tm}$, $\left.J=7.2 \mathrm{~Hz}, 1 \mathrm{H}, \mathrm{H}-3^{\prime}\right), 6.04\left(\mathrm{ddd}, J=7.3,4.3,0.8 \mathrm{~Hz}, 1 \mathrm{H}, \mathrm{H}-1^{\prime}\right), 6.99(\mathrm{~d}, J=0.8 \mathrm{~Hz}, 1 \mathrm{H}, \mathrm{H}-3), 7.18(\mathrm{~s}, 2 \mathrm{H}$, H-6, H-7), 12.42 (s, 1H, C5-OH), $12.58(\mathrm{~s}, 1 \mathrm{H}, \mathrm{C} 8-\mathrm{OH}) ;{ }^{13} \mathrm{C}-\mathrm{NMR}\left(\mathrm{CDCl}_{3}\right): \delta 18.0\left(\mathrm{C}-6^{\prime}\right), 25.7\left(\mathrm{C}-5^{\prime}\right), 2$ $\times 26.0,26.1\left(\mathrm{C}-3^{\prime \prime}, \mathrm{C}-4^{\prime \prime}, \mathrm{C}-5^{\prime \prime}\right), 3 \times 33.0\left(\mathrm{C}-2^{\prime}, \mathrm{C}-2^{\prime \prime}, \mathrm{C}-6^{\prime \prime}\right), 35.0\left(\mathrm{C}-1^{\prime \prime}\right), 42.1(\mathrm{C}-\alpha), 69.2\left(\mathrm{C}-1^{\prime}\right), 111.6$ (C-4a), 111.8 (C-8a), 117.9 (C-3'), 131.5 (C-3), 132.7 (C-7), 132.8 (C-6), 136.0 (C-4'), 148.5 (C-2), 166.9 (C-5), 167.4 (C-8), 171.8 (COO), 176.8 (C-1), 178.3 (C-4); MS (ESI $\left.{ }^{-}\right) \mathrm{m} / z(\%): 845$ (12) [2(M - H)+Na] $]^{-}$, $412.29(75)[\mathrm{M}]^{-}, 411.12(100)[\mathrm{M}-\mathrm{H}]^{-} ;[\mathrm{M}]^{-}$calculated for $\mathrm{C}_{24} \mathrm{H}_{28} \mathrm{O}_{6}: 412.1886$.

(R)-1-(1,4-Dihydro-5,8-dihydroxy-1,4-dioxonaphthalen-2-yl)-4-methylpent-3-enyl 1-cyclohexen-1-ylacetate (10): $50 \mu \mathrm{mol}$ Shikonin, $0.12 \mathrm{mmol}$ DCC, $15 \mu \mathrm{mol}$ DMAP, and $53 \mu \mathrm{mol} 1$-cyclohexen-1-ylacetic acid (11a); reaction time $13 \mathrm{~h}$; PTLC on silica with cyclohexane $/ \mathrm{CH}_{2} \mathrm{Cl}_{2}=1: 1$ (three times developed); 10, yield 5\%. 10: $\mathrm{R}_{\mathrm{f}}=0.48$ (silica, cyclohexane $\left./ \mathrm{CH}_{2} \mathrm{Cl}_{2}=1: 4\right)$; IR (ATR): $2926(\mathrm{~m}), 2857(\mathrm{w}), 2837(\mathrm{w}), 1738(\mathrm{~m})$, $1608(\mathrm{~s}), 1569(\mathrm{~m}), 1436(\mathrm{~m}), 1409(\mathrm{~m}), 1335(\mathrm{~m}), 1229(\mathrm{~s}), 1202(\mathrm{~s}), 1147(\mathrm{~m}), 1112(\mathrm{~m}), 777(\mathrm{~m}) \mathrm{cm}^{-1}$; ${ }^{1} \mathrm{H}-\mathrm{NMR}\left(\mathrm{CDCl}_{3}\right): 1.51-1.68\left(\mathrm{~m}, 4 \mathrm{H}, \mathrm{H}-4^{\prime \prime}, \mathrm{H}-5^{\prime \prime}\right), 1.55\left(\mathrm{~s}, 3 \mathrm{H}, \mathrm{H}-6^{\prime}\right), 1.69\left(\mathrm{~s}, 3 \mathrm{H}, \mathrm{H}-5^{\prime}\right), 1.97-2.03(\mathrm{~m}$, 2H, H-6" $6^{\prime \prime}, 2.03-2.09\left(\mathrm{~m}, 2 \mathrm{H}, \mathrm{H}-3^{\prime \prime}\right), 2.47\left(\mathrm{dtm}, J=15.1,7.6 \mathrm{~Hz}, 1 \mathrm{H}, \mathrm{H}-2^{\prime}\right), 2.62(\mathrm{dtm}, J=15.0,5.7 \mathrm{~Hz}$, $\left.1 \mathrm{H}, \mathrm{H}-2^{\prime}\right), 3.01(\mathrm{~s}, 2 \mathrm{H}, \mathrm{H}-\alpha), 5.13\left(\mathrm{tm}, J=7.2 \mathrm{~Hz}, 1 \mathrm{H}, \mathrm{H}-3^{\prime}\right), 5.62\left(\mathrm{~s} \mathrm{br}, 1 \mathrm{H}, \mathrm{H}-2^{\prime \prime}\right), 6.01$ (ddd, J = 6.5, 3.5, $\left.0.9 \mathrm{~Hz}, 1 \mathrm{H}, \mathrm{H}-1^{\prime}\right), 6.97$ (d, J = 1.0 Hz, 1H, H-3), 7.18 (s, 2H, H-6, H-7), 12.42 (s, 1H, C5-OH), 12.57 (s, 1H, $\mathrm{C} 8-\mathrm{OH}) ;{ }^{13} \mathrm{C}-\mathrm{NMR}\left(\mathrm{CDCl}_{3}\right)$ : $\delta 18.0\left(\mathrm{C}-6^{\prime}\right), 21.9\left(\mathrm{C}-5^{\prime \prime}\right), 22.7\left(\mathrm{C}-4^{\prime \prime}\right), 25.3\left(\mathrm{C}-3^{\prime \prime}\right), 25.8\left(\mathrm{C}-5^{\prime}\right), 28.6\left(\mathrm{C}-6^{\prime}\right)$, $32.9\left(\mathrm{C}-2^{\prime}\right), 43.6(\mathrm{C}-\alpha), 69.5\left(\mathrm{C}-1^{\prime}\right), 111.6(\mathrm{C}-4 \mathrm{a}), 111.9(\mathrm{C}-8 \mathrm{a}), 117.9\left(\mathrm{C}-3^{\prime}\right), 126.5\left(\mathrm{C}-2^{\prime \prime}\right), 130.6\left(\mathrm{C}-1^{\prime \prime}\right)$, 131.4 (C-3), 132.7 (C-7), 132.9 (C-6), 136.0 (C-4'), 148.4 (C-2), 167.0 (C-5), 167.5 (C-8), 170.7 (COO), 176.7 (C-1), $\left.178.2(\mathrm{C}-4) ; \mathrm{MS}_{\left(\mathrm{ESI}^{-}\right)}\right) \mathrm{m} / z(\%): 841$ (5) [2(M - H) + Na] $]^{-}, 410.23(35)[\mathrm{M}]^{-}, 409.33(100)[\mathrm{M}-$ $\mathrm{H}]^{-} ;[\mathrm{M}]^{-}$calculated for $\mathrm{C}_{24} \mathrm{H}_{26} \mathrm{O}_{6}: 410.1729$.

(R)-1-(1,4-Dihydro-5,8-dihydroxy-1,4-dioxonaphthalen-2-yl)-4-methylpent-3-enyl cyclopropanecarboxylate (11): $0.1 \mathrm{mmol}$ Shikonin, $0.15 \mathrm{mmol}$ DCC, $25 \mu \mathrm{mol}$ DMAP, and $0.1 \mathrm{mmol}$ cyclopropanecarboxylic acid (11a); reaction time $22 \mathrm{~h}$; $\mathrm{CC}$ on silica $(7 \mathrm{~g})$ with cyclohexane $/ \mathrm{CH}_{2} \mathrm{Cl}_{2}=1: 1$ to $1: 4 ; \mathbf{1 1}$, yield 20\%. 11: $\mathrm{R}_{\mathrm{f}}=0.28$ (silica, cyclohexane $/ \mathrm{CH}_{2} \mathrm{Cl}_{2}=1: 4$ ); NMR data fit with literature [20].

(R)-1-(1,4-Dihydro-5,8-dihydroxy-1,4-dioxonaphthalen-2-yl)-4-methylpent-3-enyl cyclobutanecarboxylate (12): $0.1 \mathrm{mmol}$ Shikonin, $0.15 \mathrm{mmol}$ DCC, $25 \mu \mathrm{mol}$ DMAP, and $0.1 \mathrm{mmol}$ cyclobutane carboxylic acid (12a); reaction time $22 \mathrm{~h}$; double PTLC on silica with cyclohexane $/ \mathrm{CH}_{2} \mathrm{Cl}_{2}=1: 4 ; 12$, yield $40 \% .12: \mathrm{R}_{\mathrm{f}}=0.35$ (silica, cyclohexane $/ \mathrm{CH}_{2} \mathrm{Cl}_{2}$ = 1:4); IR (ATR): $2980(\mathrm{w}), \approx 2950(\mathrm{vbr}), 2947(\mathrm{~m}), 2866(\mathrm{w}), 1736$ (s), 1611 (vs), 1570 (m), 1455 (s), 1204 (s), 1162 (s), 787 (w) cm ${ }^{-1} ;{ }^{1} \mathrm{H}-\mathrm{NMR}\left(\mathrm{CDCl}_{3}\right): 1.58$ (s, 3H, H-6'), 1.69 (s, 3H,

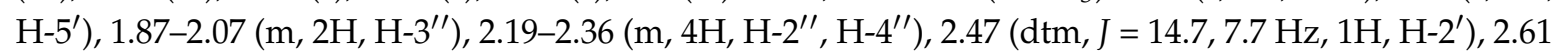
$\left(\mathrm{dtm}, J=14.9,5.7 \mathrm{~Hz}, 1 \mathrm{H}, \mathrm{H}-2^{\prime}\right), 3.22$ (quintd, $\left.J=8.5,0.7 \mathrm{~Hz}, 1 \mathrm{H}, \mathrm{H}-1^{\prime \prime}\right), 5.12\left(\mathrm{tm}, J=7.3 \mathrm{~Hz}, 1 \mathrm{H}, \mathrm{H}-3^{\prime}\right)$, $6.02\left(\mathrm{ddd}, J=7.4,4.5,0.9 \mathrm{~Hz}, 1 \mathrm{H}, \mathrm{H}-\mathrm{-}^{\prime}\right), 6.96$ (d, J = $\left.1.0 \mathrm{~Hz}, 1 \mathrm{H}, \mathrm{H}-3\right), 7.18$ (s, 2H, H-6, H-7), 12.43 (s, 1H, C5-OH), 12.59 (s, 1H, C8-OH); ${ }^{13} \mathrm{C}-\mathrm{NMR}\left(\mathrm{CDCl}_{3}\right): \delta 17.9\left(\mathrm{C}-6^{\prime}\right), 18.4\left(\mathrm{C}-3^{\prime \prime}\right), 25.1,25.2\left(\mathrm{C}-2^{\prime \prime}, \mathrm{C}-4^{\prime \prime}\right), 25.8$ (C-5'), $32.9\left(\mathrm{C}-2^{\prime}\right), 38.0\left(\mathrm{C}-1^{\prime \prime}\right), 69.0\left(\mathrm{C}-1^{\prime}\right), 111.6$ (C-4a), 111.8 (C-8a), 117.8 (C-3'), $131.4(\mathrm{C}-3), 132.6$ (C-7), 132.8 (C-6), 136.0 (C-4'), 148.5 (C-2), 166.7 (C-5), 167.2 (C-8), 174.1 (COO), 176.9 (C-1), 178.4 (C-4); MS 
$\left(\mathrm{ESI}^{-}\right) \mathrm{m} / z(\%): 1165(3)\left[3 \mathrm{M}-3 \mathrm{H}+\mathrm{Na}+\mathrm{K}^{-}, 1147(6)[3 \mathrm{M}-2 \mathrm{H}+\mathrm{K}]^{-}, 1231(8)[3 \mathrm{M}-2 \mathrm{H}+\mathrm{Na}]^{-}\right.$, $370.11(42)[\mathrm{M}]^{-}, 369.17(100)[\mathrm{M}-\mathrm{H}]^{-}$; $[\mathrm{M}]^{-}$calculated for $\mathrm{C}_{21} \mathrm{H}_{22} \mathrm{O}_{6}: 370.1416$.

(R)-1-(1,4-Dihydro-5,8-dihydroxy-1,4-dioxonaphthalen-2-yl)-4-methylpent-3-enyl cyclopentanecarboxylate (13): $0.1 \mathrm{mmol}$ Shikonin, $0.15 \mathrm{mmol}$ DCC, $25 \mu \mathrm{mol}$ DMAP, and $0.1 \mathrm{mmol}$ cyclopentanecarboxylic acid (13a); reaction time $17 \mathrm{~h}$; double PTLC on silica with cyclohexane $/ \mathrm{CH}_{2} \mathrm{Cl}_{2}=1: 4 ; 13$, yield $41 \%$. 13: $\mathrm{R}_{\mathrm{f}}=0.32$ (silica, cyclohexane $/ \mathrm{CH}_{2} \mathrm{Cl}_{2}$ = 1:4); IR (ATR): 3050 (w), $2954(\mathrm{~m}), 2919$ (w), $2870(\mathrm{w}), 1737$ (s), 1608 (s), $1570(\mathrm{~m}), 1452(\mathrm{~m}), 1205$ (s), 1141 (s), $767(\mathrm{~m}) \mathrm{cm}^{-1},{ }^{1} \mathrm{H}-\mathrm{NMR}\left(\mathrm{CDCl}_{3}\right): 1.58$ (s, 3H, H-6 $\left.{ }^{\prime}\right), 1.57-1.66$ $\left(\mathrm{m}, 2 \mathrm{H}, \mathrm{H}-3^{\prime \prime}, \mathrm{H}-4^{\prime \prime}\right), 1.66-1.75\left(\mathrm{~m}, 2 \mathrm{H}, \mathrm{H}-3^{\prime \prime}, \mathrm{H}-4^{\prime \prime}\right), 1.69$ (s, 3H, H-5'), 1.75-1.87 (m, 2H, H-2 $\left.{ }^{\prime \prime}, \mathrm{H}-5^{\prime \prime}\right)$, 1.87-1.99 (m, 2H, H-2", $\left.\mathrm{H}-5^{\prime \prime}\right), 2.47\left(\mathrm{dtm}, J=14.7,7.5 \mathrm{~Hz}, 1 \mathrm{H}, \mathrm{H}-2^{\prime}\right), 2.62(\mathrm{dtm}, J=14.8,5.7 \mathrm{~Hz}, 1 \mathrm{H}$, $\left.\mathrm{H}-2^{\prime}\right), 2.82\left(\mathrm{tt}, J=7.3,8.4 \mathrm{~Hz}, 1 \mathrm{H}, \mathrm{H}-1^{\prime \prime}\right), 5.12\left(\mathrm{tm}, J=7.3 \mathrm{~Hz}, 1 \mathrm{H}, \mathrm{H}-3^{\prime}\right), 6.02(\mathrm{ddd}, J=7.3,4.4,0.8 \mathrm{~Hz}, 1 \mathrm{H}$, H-1'), 6.98 (d, J = 0.9 Hz, 1H, H-3), 7.19 (s, 2H, H-6, H-7), 12.43 (s, 1H, C5-OH), 12.59 (s, 1H, C8-OH); ${ }^{13} \mathrm{C}-\mathrm{NMR}\left(\mathrm{CDCl}_{3}\right): \delta 18.0\left(\mathrm{C}-6^{\prime}\right), 2 \times 25.8\left(\mathrm{C}-5^{\prime}, \mathrm{C}-3^{\prime \prime}, \mathrm{C}-4^{\prime \prime}\right), 29.9,30.0\left(\mathrm{C}-2^{\prime \prime}, \mathrm{C}-5^{\prime \prime}\right), 33.0\left(\mathrm{C}-2^{\prime}\right), 43.8$ $\left(\mathrm{C}-1^{\prime \prime}\right), 69.0\left(\mathrm{C}-1^{\prime}\right), 111.6$ (C-4a), 111.8 (C-8a), 117.8 (C-3'), 131.4 (C-3), 132.6 (C-7), 132.8 (C-6), 135.9 (C-4'), 148.7 (C-2), 166.7 (C-5), 167.2 (C-8), 175.4 (COO), 176.9 (C-1), 178.5 (C-4); MS (ESI ${ }^{-}$) m/z (\%): $1189(7)\left[3 \mathrm{M}-2 \mathrm{H}+\mathrm{K}^{-}, 384.13(62)\left[\mathrm{M}^{-}\right], 383.28(100)[\mathrm{M}-\mathrm{H}]^{-}\right.$; $[\mathrm{M}]^{-}$calculated for $\mathrm{C}_{22} \mathrm{H}_{24} \mathrm{O}_{6}$ : 384.1573 .

(R)-1-(1,4-Dihydro-5,8-dihydroxy-1,4-dioxonaphthalen-2-yl)-4-methylpent-3-enyl cyclohexanecarboxylate (14): $50 \mu \mathrm{mol}$ Shikonin, $0.12 \mathrm{mmol}$ DCC, $15 \mu \mathrm{mol}$ DMAP, and $53 \mu \mathrm{mol}$ cyclohexanecarboxylic acid (14a); reaction time $16 \mathrm{~h}$; PTLC on silica with cyclohexane $/ \mathrm{CH}_{2} \mathrm{Cl}_{2}=1: 4$ (twice developed) and an additional PTLC on silica (developed twice with cyclohexane $/ \mathrm{CH}_{2} \mathrm{Cl}_{2}=1: 1$ and twice with cyclohexane $/ \mathrm{CH}_{2} \mathrm{Cl}_{2}$ $=1: 2$ ); 14, yield 10\%. 14: $\mathrm{R}_{\mathrm{f}}=0.24$ (silica, cyclohexane $\left./ \mathrm{CH}_{2} \mathrm{Cl}_{2}=1: 4\right) ; \mathrm{IR}$ (ATR): 2927 (m), $\approx 2950$ (br), 2852 (w), 1736 (s), 1609 (s), 1570 (m), 1451 (m), 1230 (m), 1203 (m), 1162 (m), 1159 (s) cm ${ }^{-1}$; ${ }^{1} \mathrm{H}-\mathrm{NMR}$ $\left(\mathrm{CDCl}_{3}\right)$ : 1.18-1.38 (m, 3H, H-3" ax, H-4" ax, H-5" ax), 1.40-1.54 (m, 2H, H-2" ax, H-6" ax), 1.58 (s, 3H, H-6'), 1.62-1.69 (m, 1H, H-4" eq), 1.69 (s, 3H, H-5'), 1.74-1.81 (m, 2H, H-3"'eq, H-5"'eq), 1.94 (dm, $J=11.9 \mathrm{~Hz}, 2 \mathrm{H}, \mathrm{H}-2^{\prime \prime}$ eq, H-6"eq), $2.38\left(\mathrm{tt}, J=11.2,3.7 \mathrm{~Hz}, 1 \mathrm{H}, \mathrm{H}-1^{\prime \prime}\right), 2.47(\mathrm{dtm}, J=15.0,7.3 \mathrm{~Hz}, 1 \mathrm{H}$, H-2'), $2.61\left(\mathrm{dtm}, J=14.8,5.8 \mathrm{~Hz}, 1 \mathrm{H}, \mathrm{H}-2^{\prime}\right), 5.12\left(\mathrm{tm}, J=7.3 \mathrm{~Hz}, 1 \mathrm{H}, \mathrm{H}-3^{\prime}\right), 6.03(\mathrm{ddd}, J=7.3,4.5,0.9 \mathrm{~Hz}$, $\left.1 \mathrm{H}, \mathrm{H}-1^{\prime}\right), 6.97$ (d, J = 1.0 Hz, 1H, H-3), 7.18 (s, 2H, H-6, H-7), 12.43 (s, 1H, C5-OH), 12.58 (s, 1H, C8-OH); ${ }^{13} \mathrm{C}-\mathrm{NMR}\left(\mathrm{CDCl}_{3}\right): \delta 18.0\left(\mathrm{C}-6^{\prime}\right), 2 \times 25.4\left(\mathrm{C}-3^{\prime \prime}, \mathrm{C}-5^{\prime \prime}\right), 25.7\left(\mathrm{C}-4^{\prime \prime}\right), 26.9\left(\mathrm{C}-5^{\prime}\right), 28.9,29.0\left(\mathrm{C}-2^{\prime \prime}, \mathrm{C}-6^{\prime \prime}\right)$, $33.0\left(\mathrm{C}-2^{\prime}\right), 43.3\left(\mathrm{C}-1^{\prime \prime}\right), 68.9$ (C-1'), 111.6 (C-4a), 111.9 (C-8a), 117.8 (C-3'), 131.4 (C-3), 132.6 (C-7), 132.8 (C-6), 135.9 (C-4'), 148.7 (C-2), 166.7 (C-5), 167.3 (C-8), 174.7 (COO), 177.0 (C-1), 178.5 (C-4); MS (ESI-) $m / z(\%): 817(5)[2(\mathrm{M}-\mathrm{H})+\mathrm{Na}]^{-}, 398.16(51)[\mathrm{M}]^{-}, 397.28(100)[\mathrm{M}-\mathrm{H}]^{-} ;[\mathrm{M}]^{-}$calculated for $\mathrm{C}_{23} \mathrm{H}_{26} \mathrm{O}_{6}: 398.1729$.

(R)-1-(1,4-Dihydro-5,8-dihydroxy-1,4-dioxonaphthalen-2-yl)-4-methylpent-3-enyl cyclohex-1-enecarboxylate (15): $0.1 \mathrm{mmol}$ Shikonin, $0.17 \mathrm{mmol}$ DCC, $25 \mu \mathrm{mol}$ DMAP, and $0.1 \mathrm{mmol}$ cyclohex-1-enecarboxylic acid (15a); reaction time $16 \mathrm{~h}$; PTLC on silica (developed twice with cyclohexane $/ \mathrm{CH}_{2} \mathrm{Cl}_{2}=2: 1$ and one time with cyclohexane $/ \mathrm{CH}_{2} \mathrm{Cl}_{2}=1: 2$ ) and an additional PTLC on silica (developed twice with cyclohexane $/ \mathrm{CH}_{2} \mathrm{Cl}_{2}=2: 1$ ); 15, yield $13 \%$. 15: $\mathrm{R}_{\mathrm{f}}=0.37$ (silica, cyclohexane / $\mathrm{CH}_{2} \mathrm{Cl}_{2}=1: 4$ ); IR (ATR):

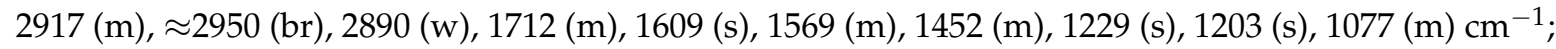
${ }^{1} \mathrm{H}-\mathrm{NMR}\left(\mathrm{CDCl}_{3}\right): 1.57$ (s, 3H, H-6'), 1.60-1.69 (m, 4H, H-4" $\left.{ }^{\prime \prime} \mathrm{H}-5^{\prime \prime}\right), 1.69$ (s, 3H, H-5'), 2.20-2.32 (m, $\left.4 \mathrm{H}, \mathrm{H}-3^{\prime}, \mathrm{H}-6^{\prime \prime}\right), 2.52\left(\mathrm{dtm}, J=15.0,7.2 \mathrm{~Hz}, 1 \mathrm{H}, \mathrm{H}-2^{\prime}\right), 2.64\left(\mathrm{dtm}, J=15.1,5.4 \mathrm{~Hz}, 1 \mathrm{H}, \mathrm{H}-2^{\prime}\right), 5.14(\mathrm{tm}$, $\left.J=7.2 \mathrm{~Hz}, 1 \mathrm{H}, \mathrm{H}-3^{\prime}\right), 6.03\left(\mathrm{ddd}, J=7.1,4.6,0.8 \mathrm{~Hz}, 1 \mathrm{H}, \mathrm{H}-1^{\prime}\right), 6.96(\mathrm{~d}, J=1.0 \mathrm{~Hz}, 1 \mathrm{H}, \mathrm{H}-3), 7.09$ (m, 1H, $\left.\mathrm{H}-2^{\prime \prime}\right), 7.19$ (s, 2H, H-6, H-7), 12.43 (s, 1H, C5-OH), 12.59 (s, 1H, C8-OH) ${ }^{13} \mathrm{C}-\mathrm{NMR}\left(\mathrm{CDCl}_{3}\right): \delta 18.0$ $\left(\mathrm{C}-6^{\prime}\right), 21.4,22.0\left(\mathrm{C}-5^{\prime \prime}, \mathrm{C}-4^{\prime \prime}\right), 24.1\left(\mathrm{C}-3^{\prime \prime *}\right), 25.8\left(\mathrm{C}-5^{\prime}\right), 25.9\left(\mathrm{C}-6^{\prime \prime *}\right), 32.9\left(\mathrm{C}-2^{\prime}\right), 69.2\left(\mathrm{C}-1^{\prime}\right), 111.6(\mathrm{C}-4 \mathrm{a})$,

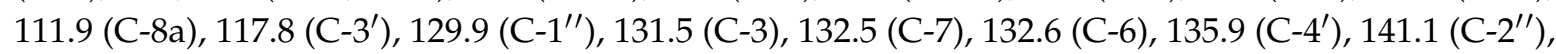
148.9 (C-2), 166.1 (COO), 166.3 (C-5), 166.9 (C-8), 177.4 (C-1), 178.9 (C-4); MS (ESI ${ }^{-}$) m/z (\%): 813 (11) $[2(\mathrm{M}-\mathrm{H})+\mathrm{Na}]^{-}, 396.24(44)[\mathrm{M}]^{-}, 395.29(100)[\mathrm{M}-\mathrm{H}]^{-} ;[\mathrm{M}]^{-}$calculated for $\mathrm{C}_{23} \mathrm{H}_{24} \mathrm{O}_{6}: 396.1573$.

(R)-1-(1,4-Dihydro-5,8-dihydroxy-1,4-dioxonaphthalen-2-yl)-4-methylpent-3-enyl cyclohex-3-enecarboxylate (16): $0.1 \mathrm{mmol}$ Shikonin, $0.20 \mathrm{mmol} \mathrm{DCC}, 30 \mu \mathrm{mol}$ DMAP, and $0.1 \mathrm{mmol}$ cyclohex-3-enecarboxylic 
acid (16a); reaction time $16 \mathrm{~h}$; two subsequent PTLC on silica each one developed twice with cyclohexane $/ \mathrm{CH}_{2} \mathrm{Cl}_{2}=2: 1$ and twice with cyclohexane $\left./ \mathrm{CH}_{2} \mathrm{Cl}_{2}=1: 2\right)$; 16, yield: $29 \%$. 16: 1:1 mixture of diastereomers; $\mathrm{R}_{\mathrm{f}}=0.28$ (silica, $\mathrm{CH}_{2} \mathrm{Cl}_{2}$ ); IR (ATR): 3025 (vw), 2917 (m), $\approx 2950$ (br), 2849 (w), 1735 (s), 1608 (s), $1568(\mathrm{~m}), 1452(\mathrm{~m}), 1220(\mathrm{~s}), 1201$ (s), $1155(\mathrm{~s}) \mathrm{cm}^{-1} ;{ }^{1} \mathrm{H}-\mathrm{NMR}\left(\mathrm{CDCl}_{3}\right): 1.59$ (s, 3H, H-6 $), 1.70$ $\left(\mathrm{s}, 3 \mathrm{H}, \mathrm{H}-5^{\prime}\right), 1.68-1.81\left(\mathrm{~m}, 1 \mathrm{H}, \mathrm{H}-6^{\prime \prime}\right), 2.00-2.08\left(\mathrm{~m}, 1 \mathrm{H}, \mathrm{H}-6^{\prime \prime}\right), 2.10-2.17$ (m, 2H, H-5 $\left.{ }^{\prime \prime}\right), 2.26-2.32$ (m, $\left.2 \mathrm{H}, \mathrm{H}-2^{\prime \prime}\right), 2.49\left(\mathrm{dtm}, J=15.0,7.3 \mathrm{~Hz}, 1 \mathrm{H}, \mathrm{H}-2^{\prime}\right), 2.59-2.71\left(\mathrm{~m}, 2 \mathrm{H}, \mathrm{H}-2^{\prime}\right.$ and $\left.\mathrm{H}-1^{\prime \prime}\right), 5.13(\mathrm{tm}, J=6.6 \mathrm{~Hz}$, $\left.1 \mathrm{H}, \mathrm{H}-3^{\prime}\right), 5.66-5.76\left(\mathrm{~m}, 2 \mathrm{H}, \mathrm{H}-3^{\prime \prime}, \mathrm{H}-4^{\prime \prime}\right), 6.05\left(\mathrm{~m}, 1 \mathrm{H}, \mathrm{H}-1^{\prime}\right), 6.98(2 \mathrm{~d}, 1 \mathrm{H}, \mathrm{J} \approx 1 \mathrm{~Hz}, \mathrm{H}-3), 7.19(\mathrm{~s}, 2 \mathrm{H}$, H-6, H-7), 12.42 (s, 1H, C5-OH), $12.58(2 \mathrm{~s}, 1 \mathrm{H}, \mathrm{C} 8-\mathrm{OH}) ;{ }^{13} \mathrm{C}-\mathrm{NMR}\left(\mathrm{CDCl}_{3}\right): \delta 18.0\left(\mathrm{C}-6^{\prime}\right), 24.2$ and $24.3\left(\mathrm{C}-5^{\prime \prime}\right), 24.9$ and $25.0\left(\mathrm{C}-6^{\prime \prime}\right), 25.8\left(\mathrm{C}-5^{\prime}\right), 27.3,27.4\left(\mathrm{C}-2^{\prime \prime}\right), 33.0\left(\mathrm{C}-2^{\prime}\right), 2 \times 39.3\left(\mathrm{C}-1^{\prime \prime}\right), 69.1,69.2$ (C-1') $111.6(\mathrm{C}-4 \mathrm{a}), 111.8(\mathrm{C}-8 \mathrm{a}), 117.7,117.8\left(\mathrm{C}-3^{\prime}\right), 124.9,125.0\left(\mathrm{C}-3^{\prime \prime}\right), 2 \times 126.8\left(\mathrm{C}-4^{\prime \prime}\right), 131.3(\mathrm{C}-3), 2$ $\times 132.7(\mathrm{C}-7), 2 \times 132.9(\mathrm{C}-6), 136.0\left(\mathrm{C}-4^{\prime}\right), 2 \times 148.5(\mathrm{C}-2), 2 \times 167.0(\mathrm{C}-5), 167.5,167.6$ (C-8), 174.4,

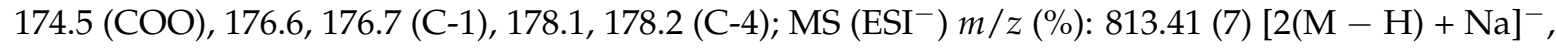
$395.16[\mathrm{M}-\mathrm{H}]^{-} ;[\mathrm{M}-\mathrm{H}]^{-}$calculated for $\mathrm{C}_{23} \mathrm{H}_{24} \mathrm{O}_{6}: 395.1495$.

(R)-1-(1,4-Dihydro-5,8-dihydroxy-1,4-dioxonaphthalen-2-yl)-4-methylpent-3-enyl trans 2-methylcyclopropanecarboxylate (17): $0.1 \mathrm{mmol}$ Shikonin, $0.2 \mathrm{mmol}$ DCC, $82 \mu \mathrm{mol}$ DMAP, and $0.11 \mathrm{mmol} 2$-methyl-cyclopropane carboxylic acid (cis/trans mixture ca. 1:3,5) (17a); reaction time $15 \mathrm{~h}$; CC on silica $(7 \mathrm{~g})$ with cyclohexane $/ \mathrm{CH}_{2} \mathrm{Cl}_{2}=2: 1$ to 0:1 and PTLC on silica with cyclohexane $/ \mathrm{CH}_{2} \mathrm{Cl}_{2}=2: 1$ (five times developed); two diastereomers of 17, yield 3\%. 17: $\mathrm{R}_{\mathrm{f}}=0.26$ (silica, $\mathrm{CH}_{2} \mathrm{Cl}_{2}$ ); IR (ATR): $2960(\mathrm{w})$, $2919(\mathrm{w}), \approx 2950(\mathrm{br}), 2856(\mathrm{w}), 1732(\mathrm{~s}), 1609$ (s), $1569(\mathrm{~m}), 1559(\mathrm{~m}), 1454(\mathrm{~m}), 1406(\mathrm{~m}), 1205(\mathrm{~m})$, $1177(\mathrm{~m}), 1159$ (s), $781(\mathrm{~m}) \mathrm{cm}^{-1},{ }^{1} \mathrm{H}-\mathrm{NMR}\left(\mathrm{CDCl}_{3}\right): 0.70-0.79\left(\mathrm{~m}, 2 \mathrm{H}, 2 \times \mathrm{H}-3^{\prime \prime}\right), 1.12-1.20(\mathrm{~m}, 7 \mathrm{H}, 2 \times$ cyclopropyl- $\left.\mathrm{CH}_{3}, 1 \times \mathrm{H}-3^{\prime \prime}\right), 1.20-1.26\left(\mathrm{~m}, 1 \mathrm{H}, \mathrm{H}-3^{\prime \prime}\right), 1.36-1.48\left(\mathrm{~m}, 4 \mathrm{H}, 2 \mathrm{H}-1^{\prime \prime}, 2 \times \mathrm{H}-2^{\prime \prime}\right), 1.58(\mathrm{~s}, 6 \mathrm{H}$, H-6 $\left.{ }^{\prime}\right), 1.70\left(\mathrm{~s}, 6 \mathrm{H}, \mathrm{H}-5^{\prime}\right), 2.42-2.53\left(\mathrm{~m}, 2 \mathrm{H}, 2 \times \mathrm{H}-2^{\prime}\right), 2.57-2.66\left(\mathrm{~m}, 2 \mathrm{H}, 2 \times \mathrm{H}-2^{\prime}\right), 5.08-5.16(\mathrm{~m}, 2 \mathrm{H}, 2 \times$ H-3'), $6.00\left(\mathrm{tm}, J=5.9 \mathrm{~Hz}, 2 \mathrm{H}, \mathrm{H}-1^{\prime}\right), 6.99(\mathrm{~d}, J=0.9 \mathrm{~Hz}, 1 \mathrm{H}, \mathrm{H}-3), 7.00(\mathrm{~d}, J=0.9 \mathrm{~Hz}, 1 \mathrm{H}, \mathrm{H}-3), 7.18$ (s, 4H, H-6, H-7), 12.44 (2s, 2H, C5-OH), 12.58 (s, 2H, C8-OH); ${ }^{13} \mathrm{C}-\mathrm{NMR}\left(\mathrm{CDCl}_{3}\right): \delta 2 \times 17.2\left(\mathrm{C}-3^{\prime \prime}\right)$, $2 \times 17.7\left(\mathrm{C}-2^{\prime \prime}\right), 3 \times 17.9$ (cyclopropyl- $\left.\mathrm{CH}_{3}, \mathrm{C}-6^{\prime}\right), 2 \times 21.2\left(\mathrm{C}-1^{\prime \prime}\right), 25.8\left(\mathrm{C}-5^{\prime}\right), 32.9\left(\mathrm{C}-2^{\prime}\right), 69.2,69.3$ (C-1'), 111.6 (C-4a), 111.8 (C-8a), 117.7 (C-3'), $2 \times 131.6$ (C-3), 132.6 (C-7), 132.7 (C-6), 136.0 (C-4'), 148.6 (C-2), 166.5 (C-5), 167.0 (C-8), $2 \times 173.3$ (COO), $2 \times 177.2$ (C-1), 178.7, 178.8 (C-4); MS (ESI $\left.^{-}\right) \mathrm{m} / z(\%)$ : $761.32(12)[2(\mathrm{M}-\mathrm{H})+\mathrm{Na}]^{-}, 370.14(46)[\mathrm{M}]^{-}, 369.26(100)[\mathrm{M}-\mathrm{H}]^{-} ;[\mathrm{M}]^{-}$calculated for $\mathrm{C}_{21} \mathrm{H}_{22} \mathrm{O}_{6}$ : 370.1416.

Exo-(R)-1-(1,4-dihydro-5,8-dihydroxy-1,4-dioxonaphthalen-3-yl)-4-methylpent-3-enyl bicyclo[2 .2.1]hept-5ene-2-carboxylate (18) and endo-(R)-1-(1,4-dihydro-5,8-dihydroxy-1,4-dioxonaphthalen-3-yl)-4-methylpent-3enyl bicyclo[2.2.1]hept-5-ene-2-carboxylate (19): $0.1 \mathrm{mmol}$ Shikonin, $0.20 \mathrm{mmol}$ DCC, $25 \mu \mathrm{mol}$ DMAP, and $0.11 \mathrm{mmol}$ bicyclo[2.2.1]hept-5-ene-2-carboxylic acid (Exo (18a)/Endo (19a)/ = 1.0:4.1); reaction time $16 \mathrm{~h}$; PTLC on silica (developed three times with cyclohexane $/ \mathrm{CH}_{2} \mathrm{Cl}_{2}=2: 1$ and one time with cyclohexane $/ \mathrm{CH}_{2} \mathrm{Cl}_{2}=1: 2$ ) and PTLC on silica (developed twice with cyclohexane $/ \mathrm{CH}_{2} \mathrm{Cl}_{2}=2: 1$ and three times with cyclohexane $/ \mathrm{CH}_{2} \mathrm{Cl}_{2}=1: 2$ ), yield: $18,6 \%$ and $1910 \%$. 18: 1:1 mixture of diastereomers, $\mathrm{R}_{\mathrm{f}}=0.31$ (silica, cyclohexane $\left./ \mathrm{CH}_{2} \mathrm{Cl}_{2}=1: 4\right)$; IR (ATR): $2972(\mathrm{w}), 2917(\mathrm{~m}), \approx 2950(\mathrm{br})$, $2850(\mathrm{w}), 1734(\mathrm{~m}), 1609$ (s), $1568(\mathrm{~m}), 1453(\mathrm{~m}), 1230(\mathrm{~m}), 1203(\mathrm{~m}), 1163(\mathrm{~s}), 1147(\mathrm{~m}) \mathrm{cm}^{-1},{ }^{1} \mathrm{H}-\mathrm{NMR}$

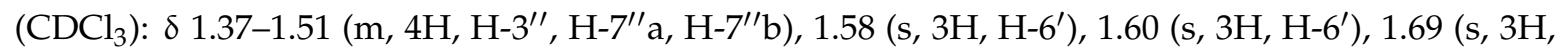
$\left.\mathrm{H}-5^{\prime}\right), 1.70\left(\mathrm{~s}, 3 \mathrm{H}, \mathrm{H}-5^{\prime}\right), 1.88-1.95\left(\mathrm{~m}, 2 \mathrm{H}, \mathrm{H}-3^{\prime \prime}\right), 2.28-2.34\left(\mathrm{~m}, 2 \mathrm{H}, \mathrm{H}-2^{\prime \prime}\right), 2.48(\mathrm{dt}, J=14.8,2 \mathrm{H}, 7.7 \mathrm{~Hz}$, H-2'), $2.62\left(\mathrm{dt}, J=15.0,2 \mathrm{H}, 5.7 \mathrm{~Hz}, \mathrm{H}-2^{\prime}\right) ; 2.94\left(\mathrm{~s}, \mathrm{br}, 2 \mathrm{H}, \mathrm{H}-4^{\prime \prime}\right), 3.06\left(\mathrm{~s}, \mathrm{br}, 1 \mathrm{H}, \mathrm{H}-1^{\prime \prime}\right), 3.08(\mathrm{~s}, \mathrm{br}, 1 \mathrm{H}$, $\left.\mathrm{H}-1^{\prime \prime}\right), 5.13\left(\mathrm{tm}, J=7.3 \mathrm{~Hz}, 1 \mathrm{H}, \mathrm{H}-3^{\prime}\right), 5.15\left(\mathrm{tm}, J=7.3 \mathrm{~Hz}, 1 \mathrm{H}, \mathrm{H}-3^{\prime}\right), 6.04\left(\mathrm{td}, J=4.3,0.9 \mathrm{~Hz}, 1 \mathrm{H}, \mathrm{H}-1^{\prime}\right)$, $6.06\left(\mathrm{td}, J=4.4,0.9 \mathrm{~Hz}, 1 \mathrm{H}, \mathrm{H}-1^{\prime}\right), 6.12-6.20\left(\mathrm{~m}, 4 \mathrm{H}, \mathrm{H}-5^{\prime \prime}, \mathrm{H}-6^{\prime \prime}\right), 7.00(\mathrm{~d}, J=1.0 \mathrm{~Hz}, 1 \mathrm{H}, \mathrm{H}-3), 7.01(\mathrm{~d}$, $J=1.0 \mathrm{~Hz}, 1 \mathrm{H}, \mathrm{H}-3), 6.12-6.19\left(\mathrm{~m}, 4 \mathrm{H}, \mathrm{H}-5^{\prime \prime}, \mathrm{H}-6^{\prime \prime}\right), 7.18,7.19$ (2s, 4H, H-6, H-7), 12.43 (2s, 2H, C5-OH), $12.59(2 \mathrm{~s}, 2 \mathrm{H}, \mathrm{C} 8-\mathrm{OH}) ;{ }^{13} \mathrm{C}-\mathrm{NMR}\left(\mathrm{CDCl}_{3}\right): \delta 2 \times 18.0\left(\mathrm{C}-6^{\prime}\right), 25.8\left(\mathrm{C}-5^{\prime}\right), 30.3,30.5\left(\mathrm{C}-3^{\prime \prime}\right), 33.0,33.1$ $\left(\mathrm{C}-2^{\prime}\right), 41.6,41.7\left(\mathrm{C}-4^{\prime \prime}\right), 43.1,43.3\left(\mathrm{C}-2^{\prime \prime}\right), 2 \times 46.4\left(\mathrm{C}-7^{\prime \prime}\right), 46.5,46.7\left(\mathrm{C}-1^{\prime \prime}\right), 69.2\left(\mathrm{C}-1^{\prime}\right), 111.6(\mathrm{C}-4 \mathrm{a})$, 111.9 (C-8a), 117.8, 117.9 (C-3'), $2 \times 131.4$ (C-3), $2 \times 132.7$ (C-7), $2 \times 132.9$ (C-6), $135.6\left(\mathrm{C}-6^{\prime \prime}\right), 2 \times 136.0$ (C-4') $138.2,138.3\left(\mathrm{C}-5^{\prime \prime}\right), 148.6(\mathrm{C}-2), 2 \times 166.9,167.0(\mathrm{C}-5), 2 \times 167.5(\mathrm{C}-8), 174.9,175.0$ (COO), 176.7, $176.8(\mathrm{C}-1), 2 \times 178.3(\mathrm{C}-4) ; \mathrm{MS}_{\left(\mathrm{ESI}^{-}\right)} \mathrm{m} / z(\%): 837(5)[2(\mathrm{M}-\mathrm{H})+\mathrm{Na}]^{-}, 408.18(42)[\mathrm{M}]^{-}, 407.22$ 
(100) $[\mathrm{M}-\mathrm{H}]^{-} ;[\mathrm{M}]^{-}$calculated for $\mathrm{C}_{24} \mathrm{H}_{24} \mathrm{O}_{6}$ : 408.1573. 19: 1:1 mixture of diastereomers, $\mathrm{R}_{\mathrm{f}}=0.26$ (silica, cyclohexane $/ \mathrm{CH}_{2} \mathrm{Cl}_{2}$ = 1:4); IR (ATR): $2973(\mathrm{w}), 2917(\mathrm{~m}), \approx 2950(\mathrm{br}), 2850(\mathrm{w}), 1733(\mathrm{~m}), 1609$ (s), $1569(\mathrm{~m}), 1452(\mathrm{~m}), 1231(\mathrm{~m}), 1202(\mathrm{~m}), 1165(\mathrm{~s}), 1108(\mathrm{~m}), 709(\mathrm{w}) \mathrm{cm}^{-1},{ }^{1} \mathrm{H}-\mathrm{NMR}\left(\mathrm{CDCl}_{3}\right): 1.32$

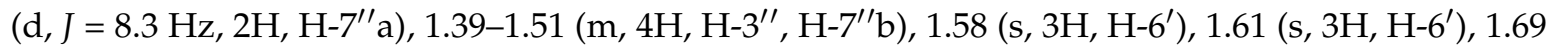
$\left.\left(\mathrm{s}, 3 \mathrm{H}, \mathrm{H}-5^{\prime}\right), 1.72\left(\mathrm{~s}, 3 \mathrm{H}, \mathrm{H}-5^{\prime}\right), 1.88-2.00 \mathrm{~m}, 2 \mathrm{H}, \mathrm{H}-3^{\prime \prime}\right), 2.46\left(\mathrm{dt}, J=14.9,7.5 \mathrm{~Hz}, 2 \mathrm{H}, \mathrm{H}-2^{\prime}\right), 2.59(\mathrm{dt}$, $\left.J=15.0,5.3 \mathrm{~Hz}, 2 \mathrm{H}, \mathrm{H}-2^{\prime}\right), 2.93\left(\mathrm{~s}, \mathrm{br}, 2 \mathrm{H}, \mathrm{H}-4^{\prime \prime}\right), 3.04\left(\mathrm{dtd}, J=8.9,4.0,1.1 \mathrm{~Hz}, 2 \mathrm{H}, \mathrm{H}-2^{\prime \prime}\right), 3.28$ (s, br, $\left.2 \mathrm{H}, \mathrm{H}_{-1}{ }^{\prime \prime}\right), 5.11\left(\mathrm{tm}, J=7.1 \mathrm{~Hz}, 1 \mathrm{H}, \mathrm{H}-3^{\prime}\right), 5.16\left(\mathrm{tm}, J=7.3 \mathrm{~Hz}, 1 \mathrm{H}, \mathrm{H}-3^{\prime}\right), 5.88(\mathrm{dd}, J=5.7,2.8 \mathrm{~Hz}, 1 \mathrm{H}$, $\left.\mathrm{H}-6^{\prime \prime}\right), 5.90\left(\mathrm{dd}, J=5.7,2.8 \mathrm{~Hz}, 1 \mathrm{H}, \mathrm{H}-6^{\prime \prime}\right), 5.94\left(\mathrm{ddd}, J=\approx 7.5,4.2,0.8 \mathrm{~Hz}, 1 \mathrm{H}, \mathrm{H}-1^{\prime}\right), 5.96(\mathrm{ddd}, J=\approx 7.5$, 4.6, 0.6 Hz, 2H, H-1'), 6.19 (dd, J = 5.7, 3.0 Hz, 1H, H-5' $), 6.22\left(\mathrm{dd}, J=5.7,3.1 \mathrm{~Hz}, 1 \mathrm{H}, \mathrm{H}-5^{\prime \prime}\right), 6.96(\mathrm{~d}$, $J=0.9 \mathrm{~Hz}, 1 \mathrm{H}, \mathrm{H}-3), 6.99$ (d, J = 0.9 Hz, 1H, H-3), 7.18 (s, 4H, H-6, H-7), 12.42 (s, 2H, C5-OH), 12.57 (2s, $\left.1 \mathrm{H}, \mathrm{C} 8-\mathrm{OH}) ;{ }^{13} \mathrm{C}-\mathrm{NMR}\left(\mathrm{CDCl}_{3}\right): \delta 2 \times 18.0\left(\mathrm{C}-6^{\prime}\right), 2 \times 25.8\left(\mathrm{C}-5^{\prime}\right), 29.0\right), 29.3\left(\mathrm{C}-3^{\prime \prime}\right), 32.9,33.0\left(\mathrm{C}-2^{\prime}\right), 2$ $\times 42.6\left(\mathrm{C}-4^{\prime \prime}\right), 2 \times 43.4\left(\mathrm{C}-2^{\prime \prime}\right), 46.0\left(\mathrm{C}-1^{\prime}\right), 49.7,49.9\left(\mathrm{C}-7^{\prime \prime}\right), 69.2,69.4\left(\mathrm{C}-1^{\prime}\right), 2 \times 111.6(\mathrm{C}-4 \mathrm{a}), 111.9$ (C-8a), 117.9, $118.1\left(\mathrm{C}-3^{\prime}\right), 131.3,131.4(\mathrm{C}-3), 132.0,132.2\left(\mathrm{C}-6^{\prime \prime}\right), 132.6,2 \times 132.8,132.9$ (C-6, C-7), 135.8, $135.9\left(\mathrm{C}-4^{\prime}\right), 138.0,138.1\left(\mathrm{C}-5^{\prime \prime}\right), 148.6(\mathrm{C}-2), 167.0$ (C-5), 167.7 (C-8), 173.6 (COO), 176.5 (COO, C-1) 176.7 (C-1), 178.2 (C-4); more polar diastereomer: MS (ESI $\left.{ }^{-}\right) \mathrm{m} / z$ (\%): 408.25 (33) [M] ${ }^{-}, 407.31(100)$ $[\mathrm{M}-\mathrm{H}]^{-}$; less polar diastereomer: MS (ESI $\left.{ }^{-}\right) m / z(\%): 408.17(43)[\mathrm{M}]^{-}, 407.21(100)[\mathrm{M}-\mathrm{H}]^{-}$; $[\mathrm{M}]^{-}$ calculated for $\mathrm{C}_{24} \mathrm{H}_{24} \mathrm{O}_{6}$ : 408.1573 .

(R)-1-(1,4-Dihydro-5,8-dihydroxy-1,4-dioxonaphthalen-2-yl)-4-methylpent-3-enyl bicyclo[2.2.1]heptane-2ylacetate (20): $50 \mu \mathrm{mol}$ Shikonin, $0.12 \mathrm{mmol}$ DCC, $15 \mu \mathrm{mol}$ DMAP, and $53 \mu \mathrm{mol}$ bicyclo[2.2.1]heptane-2ylacetic acid (20a); reaction time $16 \mathrm{~h}$; PTLC on silica with cyclohexane $/ \mathrm{CH}_{2} \mathrm{Cl}_{2}=1: 4$ (twice developed) and an additional PTLC on silica (developed twice with cyclohexane $/ \mathrm{CH}_{2} \mathrm{Cl}_{2}=1: 1$ and twice with cyclohexane $/ \mathrm{CH}_{2} \mathrm{Cl}_{2}=1: 2$ ); 20, yield $19 \%$ (sum of isomers). 20: $\mathrm{R}_{\mathrm{f}}=0.24$ (silica, cyclohexane/ $\mathrm{CH}_{2} \mathrm{Cl}_{2}$ = 1:4); IR (ATR): 2948 (m), 2917 (m), ₹2950 (br), 2868 (w), 1738 (s), 1609 (s), $1570(\mathrm{~m}), 1453(\mathrm{~m}), 1204(\mathrm{~s}), 1173(\mathrm{~m}), 1159$ (s), $783(\mathrm{~m}) \mathrm{cm}^{-1},{ }^{1} \mathrm{H}-\mathrm{NMR}\left(\mathrm{CDCl}_{3}\right): 1.06\left(\mathrm{~m}, 1 \mathrm{H}, \mathrm{H}-3^{\prime \prime}\right)$, $1.13\left(\mathrm{~m}, 1 \mathrm{H}, \mathrm{H}-7^{\prime \prime}\right), 1.15\left(\mathrm{~m}, 1 \mathrm{H}, \mathrm{H}-5^{\prime \prime}\right), 1.24\left(\mathrm{~m}, 1 \mathrm{H}, \mathrm{H}-6^{\prime \prime}\right), 1.32$ (dquint, $\left.J=9.9,1.5 \mathrm{~Hz}, 1 \mathrm{H}, \mathrm{H}-7^{\prime \prime}\right)$, $1.48\left(\mathrm{~m}, 1 \mathrm{H}, \mathrm{H}-5^{\prime \prime}\right), 1.51\left(\mathrm{~m}, 1 \mathrm{H}, \mathrm{H}-6^{\prime \prime}\right), 1.53\left(\mathrm{~m}, 1 \mathrm{H}, \mathrm{H}-3^{\prime \prime}\right), 1.58$ (s, 3H, H-6'), 1.69 (s, 3H, H-5'), 1.91 (quint, $\left.J=6.5 \mathrm{~Hz}, 1 \mathrm{H}, \mathrm{H}-2^{\prime \prime}\right), 1.98\left(\mathrm{~s}, \mathrm{br}, 1 \mathrm{H}, \mathrm{H}-1^{\prime \prime}\right), 2.20(\mathrm{~m}, 1 \mathrm{H}, \mathrm{H}-\alpha), 2.23\left(\mathrm{~m}, 1 \mathrm{H}, \mathrm{H}-4^{\prime \prime}\right), 2.34$ (dd, $J=15.2,7.9 \mathrm{~Hz}, 1 \mathrm{H}, \mathrm{H}-\alpha), 2.46\left(\mathrm{dt}, J=15.0,7.5 \mathrm{~Hz}, 1 \mathrm{H}, \mathrm{H}-2^{\prime}\right), 2.60\left(\mathrm{dt}, J=15.5,5.2 \mathrm{~Hz}, 1 \mathrm{H}, \mathrm{H}-2^{\prime}\right), 5.12(\mathrm{t}$, $\left.J=7.2 \mathrm{~Hz}, 1 \mathrm{H}, \mathrm{H}-3^{\prime}\right), 6.02\left(\mathrm{dd}, J=7.4,4.7 \mathrm{~Hz}, 1 \mathrm{H}, \mathrm{H}-\mathrm{1}^{\prime}\right), 6.98$ (s, 1H, H-3), 7.18 (s, 2H, H-6, H-7), 12.43 (s, 1H, C5-OH), 12.58 (s, 1H, C8-OH); ${ }^{13} \mathrm{C}-\mathrm{NMR}\left(\mathrm{CDCl}_{3}\right): \delta 18.0\left(\mathrm{C}-6^{\prime}\right), 25.8\left(\mathrm{C}-5^{\prime}\right), 28.5\left(\mathrm{C}-5^{\prime \prime}\right), 29.8\left(\mathrm{C}-6^{\prime \prime}\right)$, $2 \times 33.0\left(\mathrm{C}-2^{\prime}\right), 2 \times 35.2\left(\mathrm{C}-7^{\prime \prime}\right), 36.8\left(\mathrm{C}-4^{\prime \prime}\right), 37.8,37.9\left(\mathrm{C}-3^{\prime \prime}\right), 38.5,38.6\left(\mathrm{C}-2^{\prime \prime}\right), 41.1,41.3\left(\mathrm{C}-1^{\prime \prime}\right), 2 \times$ $41.3(\mathrm{C}-\alpha), 69.2,69.3\left(\mathrm{C}-1^{\prime}\right), 111.6$ (C-4a), 111.9 (C-8a), 117.9 (C-3'), 131.4, 131.5 (C-3), 132.7 (C-7), 132.8 (C-6), $136.0\left(\mathrm{C}-4^{\prime}\right), 148.5$ (C-2), $2 \times 166.9$ (C-5), $2 \times 167.4(\mathrm{C}-8), 171.9$ (COO), $2 \times 176.8$ (C-1), $2 \times 178.3$ (C-4); $\mathrm{MS}_{\left(\mathrm{ESI}^{-}\right)}$m/z (\%): 869.37 (9) [2(M - H) + Na] $\left.{ }^{-}, 424.23(49)[\mathrm{M}]^{-}, 423.25(100)[\mathrm{M}-\mathrm{H}]^{-},^{\mathrm{M}}\right]^{-}$ calculated for $\mathrm{C}_{25} \mathrm{H}_{28} \mathrm{O}_{6}: 424.1886$.

Synthesis of carboxylic acids are described in the Supplementary Material.

\subsection{Isolation of $\beta, \beta$-dimethylacrylshikonin (1)}

Dried roots of Onosma paniculata Bureau \& Franchet (Boraginaceae) were acquired in Kunming, China at a medicinal market in October 2003. The identity of the plant material was determined by genomic analysis [46]. Compound $\mathbf{1}$ was isolated as described previously [8]. In brief, freshly ground roots were extracted with petroleum ether by exhaustive Soxhlet extraction and $\mathbf{1}$ was isolated by preparative HPLC consisting of a Varian R PrepStar SD-1 (Agilent Technologies, Santa Clara, CA, USA) with Dynamax R solvent delivery system and an absorbance detector model UV-1. A VDSpher 100 RP18 column $(250 \times 25$ mm, $10 \mu \mathrm{m})$ (VDS Optilab Chromatographie Technik GmbH, Berlin, Germany) was used as stationary phase. The mobile phase consisted of (A) water and (B) acetonitrile and the following gradient was used. 0-45 min: 70-100\% B; $45-60 \mathrm{~min}$ : $100 \%$ B. 1 was identified by NMR (Varian $400 \mathrm{MHz}$ UnityINOVA spectrometer, Varian, Palo Alto, CA, USA) and CD measurements 
(Jasco J-715 Spectropolarimeter, Eurisotop, Saint-Aubin CEDEX, France); the purity was determined by HPLC and was $95 \%$.

\subsection{Cell Culture}

Human melanoma cell lines (SBcl2, WM9, WM164, and MUG-Mel2) were cultured in RPMI 1640 medium $\left(\right.$ Gibco $^{\circledR}$, Thermo Fisher Scientific, Waltham, MA, USA), 2 mM L-glutamine (Gibco $\left.{ }^{\circledR}\right), 10 \%$ fetal bovine serum (FBS, Gibco ${ }^{\circledR}$ ), and 1\% penicillin-streptomycin (Pen/Strep, Gibco ${ }^{\circledR}$ ). Human juvenile fibroblasts were isolated from donated foreskin tissue. Pieces were excised and treated with Dispase II (Roche, Vienna, Austria). After enzymatic digestion, cells were grown in high-glucose Dulbecco's modified Eagle's medium (DMEM, Gibco ${ }^{\circledR}$ ) supplemented with $2 \mathrm{mM}$ L-glutamine, $10 \%$ FBS, and 1\% Pen/Strep. Human epithelial cells (HEK-293) were kept in Dulbecco's Modified Eagle's Medium: Nutrient Mixture F-12 (DMEM/F12, Gibco ${ }^{\circledR}$ ), 2 mM L-glutamine, 10\% FBS, and 1\% Pen/Strep. Human adult fibroblasts were kindly provided by Ass. Prof. Dr. Beate Rinner (Medical University of Graz) and culture in DMEM, 2mM L-glutamine, and 10\% FBS. All cells were kept in a humidified $5 \% \mathrm{CO}_{2}$ atmosphere at $37{ }^{\circ} \mathrm{C}$ and passaged at $90 \%$ confluence by trypsinization with $0.25 \%$ trypsin-EDTA solution $\left(\mathrm{Gibco}^{\circledR}\right)$.

\subsection{Sample Preparation for In-Vitro Experiments}

All stock solutions were prepared in ethanol, stored at $-20{ }^{\circ} \mathrm{C}$ and diluted to the respective concentrations in fresh medium before each experiment. Final ethanol concentration was $0.5 \%$ in each well. Therefore, control cells represent vehicle-treated cells ( $0.5 \%$ ethanol). This concentration did not affect the cells as shown in benchmark experiments (without ethanol).

\subsection{Cell Viability Assay (XTT)}

Cell viability was analyzed in accordance with the manufacturer's protocol (Roche Diagnostics, Mannheim, Germany; cell proliferation kit II (XTT), cat. no. 11465015 001). This assay is based on the cleavage of the yellow tetrazolium salt XTT (sodium 3'-[1-(phenylaminocarbonyl)3,4-tetrazolium]-bis(4-methoxy-6-nitro) benzene sulfonic acid hydrate) into an orange formazan dye by metabolic active cells. The color changes only in viable cells and can be directly quantified using a scanning multiwell spectrophotometer. In brief, 5000 cells/well were seeded into 96-well plates $\left(100 \mu \mathrm{L}\right.$, flat bottom) and grown for $24 \mathrm{~h}$ in a $37^{\circ} \mathrm{C}, 5 \% \mathrm{CO}_{2}$ atmosphere before various concentrations of test compounds were added. Control cells were treated with $0.5 \%$ ethanol. After $72 \mathrm{~h}, 50 \mu \mathrm{L}$ of a freshly prepared XTT solution ( $5 \mathrm{~mL}$ of XTT plus $100 \mu \mathrm{L}$ of electron coupling reagent) was added, incubated for $2 \mathrm{~h}$ or $4 \mathrm{~h}$, and analyzed using a Hidex Sense Microplate Reader (Hidex, Turku, Finland). Compound 1 served as reference $(5.0 \mu \mathrm{M})$. The assay was performed at least two times, with two or three replicates each.

\subsection{ApoTox-Glo ${ }^{\mathrm{TM}}$ Triplex Assay}

This assay was conducted following the manufacturer's instructions (Promega, Fitchburg, WI, USA, cat. no. G6320). In short, 10,000 cells/well of WM9, WM164, and MUG-Mel2 cells were seeded in 96-well plates $(100 \mu \mathrm{L}$, white, flat bottom) and treated with various concentrations of 6 for $6 \mathrm{~h}, 24 \mathrm{~h}$, and $48 \mathrm{~h}$. Staurosporine $(10.0 \mu \mathrm{M})$ served as positive control for apoptosis induction. Afterwards, $20 \mu \mathrm{L}$ of a freshly prepared viability/cytotoxicity reagent was added to each well, briefly mixed for $30 \mathrm{sec}$ by orbital shaking (300-500 rpm), and incubated for $30 \mathrm{~min}$ at $37^{\circ} \mathrm{C}$. Fluorescence was measured at $400_{\mathrm{EX}} / 505_{\mathrm{Em}}$ (viability) and $485_{\mathrm{EX}} / 520_{\mathrm{Em}}$ (cytotoxicity) by using a Hidex Sense Microplate Reader. Subsequently, $100 \mu \mathrm{L}$ of a freshly prepared Caspase-Glo ${ }^{\circledR} 3 / 7$ reagent was added to each well, briefly mixed by orbital shaking (300-500 rpm, 30 s), and incubated at room temperature for another $30 \mathrm{~min}$. Luminescence was measured using a Hidex Sense Microplate Reader. Each assay was performed at least two times, with three replicates each. 


\subsection{Western Blot Analysis}

Cells were seeded at a density of 200,000 c/mL and grown over night before the test compound was added for $24 \mathrm{~h}$. Whole cell protein extracts were prepared with lysis buffer ( $50 \mathrm{mM}$ Tris- $\mathrm{HCl}$ pH 7.4, $150 \mathrm{mM} \mathrm{NaCl}, 50 \mathrm{mM} \mathrm{NaF}, 1 \mathrm{mM}$ EDTA, 10\% NP-40, 1\% Triton- $X$, and protease inhibitors), subjected to SDS-PAGE (10 or 12\%), and blotted onto PVDF membranes (Roth, Karlsruhe, Germany). Primary antibodies against PARP, phosphoH2AX (Ser139), and $\beta$-actin were purchased from Cell Signaling Technology (Danvers, MA, USA). Blots were developed using corresponding horseradish peroxidase-conjugated secondary antibodies (Dako, Jena, Germany) at room temperature for $1 \mathrm{~h}$ and the Amersham ${ }^{\mathrm{TM}} \mathrm{ECL}^{\mathrm{TM}}$ prime Western blotting detection reagent (GE Healthcare, in accordance with the manufacturer's protocol). Chemiluminescence signals were detected by the ChemiDocTouch Imaging System (BioRad Laboratories Inc., Herkules, CA, USA). Images were processed using ImageLab 5.2 Software (BioRad Laboratories Inc.) and normalized to their loading controls.

\subsection{Caspase 3 Cleavage Measured by FACS}

Cells were seeded at a density of 200,000 c/mL and grown over night before the test compound was added for $24 \mathrm{~h}$. After incubation with 6 in presence or absence of a caspase inhibitor (Z-VAD-FMK), cells were harvested by trypsinization and fixed and permeabilized with Cytofix/CytopermTM solution (BD Biosciences, Frankling Lakes, NJ, USA). The pellet was resuspended in Perm/Wash ${ }^{\mathrm{TM}}$ buffer and stained with FITC-conjugated monoclonal active caspase 3 antibody (BD Biosciences). Finally, cells were resuspended in $1 \mathrm{~mL}$ PBS and analyzed with a LSRII ${ }^{\mathrm{TM}}$ (BD Biosciences) flow cytometer equipped with a $488 \mathrm{~nm}$ argon ion laser and a $635 \mathrm{~nm}$ red diode laser (BD Biosciences). Untreated cells were used as a negative control.

\subsection{CytoTox $96{ }^{\circledR}$ Non-Radioactive Cytotoxicity Assay (LDH Assay)}

Cell membrane integrity was analyzed using the CytoTox $96{ }^{\circledR}$ Non-Radioactive Cytotoxicity Assay (G1780, Promega, Fitchburg, WI, USA) according to the manufacturer's instructions. Aliquots $(100 \mu \mathrm{L})$ of $100,000 \mathrm{c} / \mathrm{mL}$ were seeded into 96-well plates (flat bottom), grown for $24 \mathrm{~h}$, and treated with various concentrations of $6(2.5 \mu \mathrm{M}, 5.0 \mu \mathrm{M}, 7.5 \mu \mathrm{M}$, and $10.0 \mu \mathrm{M})$ for $6 \mathrm{~h}, 24 \mathrm{~h}$, and $48 \mathrm{~h}$. To measure maximal LDH release, $10 \mu \mathrm{L}$ of 10X Lysis Solution were added to control wells $45 \mathrm{~min}$ before adding the CytoTox $96{ }^{\circledR}$ Reagent. To measure the amount of released LDH, $50 \mu \mathrm{L}$ of each well were transferred to a fresh 96-well plate and $50 \mu \mathrm{L}$ of CytoTox $96^{\circledR}$ Reagent were added followed by a $30 \mathrm{~min}$ incubation period. Finally, $50 \mu \mathrm{L}$ of Stop Solution was added and absorbance was recorded at $490 \mathrm{~nm}$ (Hidex Sense Microplate Reader). Absorbance values were corrected by background values and the percentage of LDH release was calculated using the following formula. $100 \times$ experimental LDH release (OD490)/maximum LDH release (OD490).

\subsection{Cell Cycle Analysis}

Cells $(200,000 \mathrm{c} / \mathrm{mL})$ were treated with the respective $\mathrm{IC}_{50}$ concentration for $24 \mathrm{~h}$ and harvested by trypsinization. Afterwards, they were fixed with $70 \%$ ice cold ethanol for $10 \mathrm{~min}$ and at $4{ }^{\circ} \mathrm{C}$. After washing with PBS, the cell pellet was resuspended in PI-staining buffer $(50 \mu \mathrm{L} / \mathrm{mL}$ PI, RNAse, Beckman Coulter, Brea, CA, USA) and incubated for $15 \mathrm{~min}$ at $37^{\circ} \mathrm{C}$. Cell cycle distribution was analyzed using a LSRII ${ }^{\mathrm{TM}}$ (BD Biosciences) flow cytometer.

\subsection{Statistical Analysis}

Statistical analysis was carried out using SigmaPlot 13.0 (Systat Software Inc., Chicago, IL, USA). $\mathrm{IC}_{50}$ values were determined using the four-parameter logistic curve, at least five concentrations of the test compound, and two different cell passages each tested in two or three independent wells. Results are expressed as mean \pm SEM. $P$ values $<0.05$ were considered as statistically significant. 


\section{Conclusions}

In this study, eighteen novel shikonin derivatives and one known derivative were synthesized. Afterwards, their cytotoxic effects against several melanoma and skin fibroblast cell lines were investigated. Compound $\mathbf{1}$ was chosen as reference because it was the most active isolated derivative so far. To keep close to this lead compound, the two methyl groups of the side chain of $\mathbf{1}$ were formally connected with different numbers of methylene groups and the influence of the double bond and the spacing $\mathrm{CH}$ resp. $\mathrm{CH}_{2}$ group was investigated as well. In addition, three cycloalkenyl and three bicyclic derivatives were prepared to examine the effect of unsaturation and space filling with an additional methylene moiety.

In general, all derivatives exhibited cytotoxic activity, but most of them were less active than 1. For example, the prepared cycloalkylideneacetates $\mathbf{2}$ to $\mathbf{5}$ and cycloalkylacetates $\mathbf{7}$ to $\mathbf{1 0}$ were less active against the metastatic cell lines than 1 . Furthermore, neither the removal of the spacing $\mathrm{CH}$ resp. $\mathrm{CH}_{2}$ group nor bicyclic derivatives led to an overall increase of cytotoxicity compared to 1 . However, the cyclopropane derivative 6 was considerably more active against the metastatic cell lines WM164 and MUG-Mel2 than 1. The effect was also stronger than the effect of the already known derivative 11. Therefore, 6 was pharmacologically investigated in more detail. We could show that 6 led to apoptosis induction after $24 \mathrm{~h}$ while the cell membrane was not damaged within this time and at the concentration used. Apoptosis was induced caspase dependently as shown by the ApoToxGlo ${ }^{\mathrm{TM}}$ assay, FACS experiments in combination with a caspase inhibitor, and Western blot experiments. Moreover, 6 led to double-stranded DNA breaks as shown by phosphorylation of H2AX which can lead to subsequent apoptosis induction. However, 6 did not lead to cell cycle arrest as often caused by H2AX phosphorylation. In summary, the results demonstrate that 6 could represent a novel lead compound to develop antimelanoma compounds.

Supplementary Materials: The following are available online at http:/ /www.mdpi.com/1420-3049/23/11/2820/ s1. Studies on the enantiomeric purity and associated pharmacological effects of 1 ; NMR-spectra $\left({ }^{1} \mathrm{H}\right.$ and ${ }^{13} \mathrm{C}$ or HMBC) of the new shikonin derivatives; synthesis of cycloalkylidenacetic acids $\mathbf{2 a}$ to $\mathbf{5} \mathbf{a}$ and cyclobutylacetic acid (7a); ${ }^{1} \mathrm{H}-\mathrm{NMR}$ spectra of synthesized acids; HPLC runs of synthesized compounds; results of the XTT assay.

Author Contributions: C.D. performed the XTT and ApoTox-Glo ${ }^{\mathrm{TM}}$ Triplex assay, prepared cells for FACS and Western blot measurements, analyzed liquid chromatography-mass spectroscopy (LC-MS) data and drafted the manuscript; A.H. synthesized all compounds (except for shikonin and 1), performed and analyzed NMR measurements and drafted the manuscript; B.R. and A.S. did the FACS measurements; B.L. conducted Western blotting; A.D. and R.B. analyzed and interpreted the data and contributed to drafting the manuscript; N.K. isolated compound 1, performed the LDH assay, analyzed and interpreted the data, and drafted the manuscript.

Funding: The authors acknowledge financial support by the Austrian Science Fund (FWF, P27505).

Acknowledgments: We thank Guenther Heubl (Ludwig-Maximilian-University, Munich) for the identification of the plant material using genomic analysis; Eva-Maria Pferschy-Wenzig (University of Graz, Graz) for her help with LC-MS measurements; Martin Schmid and Mag. Magdalena Taschwer (University of Graz, Graz) for performing chiral HPLC measurements; and Ing. Andrea Fleck (University of Graz, Graz) for recording the IR spectra.

Conflicts of Interest: The authors declare no conflicts of interest.

\section{References}

1. Tsao, H.; Atkins, M.B.; Sober, A.J. Management of cutaneous melanoma. N. Engl. J. Med. 2004, 351, 998-1012. [CrossRef] [PubMed]

2. Junior, T.C.T.; de Godoy, L.M.F.; de Souza, G.A.; Bonatto, D.; Otake, A.H.; de Freitas Saito, R.; Roas, J.C.; Greene, L.J.; Chammas, R. Accumulation of prohibitin is a common cellular response to different stressing stimuli and protects melanoma cells from ER stress and chemotherapy-induced cell death. Oncotarget 2017, 8, 43114-43129. [CrossRef] [PubMed]

3. Aamdal, S. Current approaches to adjuvant therapy of melanoma. Eur. J. Cancer 2011, 47, 336-337. [CrossRef]

4. Newman, D.J.; Cragg, G.M. Natural products as sources of new drugs from 1981 to 2014. J. Nat. Prod. 2016, 79, 629-661. [CrossRef] [PubMed] 
5. Zhao, Q.; Assimopoulou, A.N.; Klauck, S.M.; Damianakos, H.; Chinou, I.; Kretschmer, N.; Rious, J.L.; Papageorgiou, V.P.; Bauer, R.; Efferth, T. Inhibition of c-MYC with involvement of ERK/JNK/MAPK and AKT pathways as a novel mechanism for shikonin and its derivatives in killing leukemia cells. Oncotarget 2015, 6, 38934-38951. [CrossRef] [PubMed]

6. Hasenoehrl, C.; Schwach, G.; Ghaffari-Tabrizi-Wizsy, N.; Fuchs, R.; Kretschmer, N.; Bauer, R.; Pfragner, R. Antitumor effects of shikonin derivatives on human medullary thyroid carcinoma cells. Endocr. Connect. 2017, 6, 53-62. [CrossRef] [PubMed]

7. Zhao, Q.; Kretschmer, N.; Bauer, R.; Efferth, T. Shikonin and its derivatives inhibit the epidermal growth factor receptor signaling and synergistically kill glioblastoma cells in combination with erlotinib. Int. J. Cancer 2015, 137, 1446-1456. [CrossRef] [PubMed]

8. Kretschmer, N.; Rinner, B.; Deutsch, A.J.A.; Lohberger, B.; Knausz, H.; Kunert, O.; Blunder, M.; Boechzelt, H.; Schaider, H.; Bauer, R. Naphthoquinones from Onosma panicluata induce cell-cycle arrest and apoptosis in melanoma cells. J. Nat. Prod. 2012, 75, 865-869. [CrossRef] [PubMed]

9. Song, J.; Zhao, Z.; Fan, X.; Chen, M.; Cheng, X.; Zhang, D.; Wu, F.; Ying, X.; Ji, J. Shikonin potentiates the effect of arsenic trioxide against human hepatocellular carcinoma in vitro and in vivo. Oncotarget 2016, 7, 70504-70515. [CrossRef] [PubMed]

10. Andújar, I.; Rios, J.L.; Giner, R.M.; Recio, M.C. Pharmacological properties of shikonin-reviews of literature since 2002. Planta Med. 2013, 79, 1685-1697. [CrossRef] [PubMed]

11. Hsu, P.C.; Huang, Y.T.; Tsai, M.L.; Wang, Y.J.; Lin, J.K.; Pan, M.H. Induction of apoptosis by shikonin through coordinative modulation of the Bcl-2 family, p27, and p53, release of cytochrome c, and sequential activation of caspases in human colorectal carcinoma cells. J. Agric. Food Chem. 2004, 52, 6330-6337. [CrossRef] [PubMed]

12. Damianakos, H.; Kretschmer, N.; Syklowska-Baranek, K.; Pietrosiuk, A.; Bauer, R.; Chinou, I. Antimicrobial and cytotoxic isohexenylnapththazarins from Arnebia euchroma (Royle) Johnst. (Boraginaceae) callus and cell suspension culture. Molecules 2012, 17, 14310-14322. [CrossRef] [PubMed]

13. Cui, X.R.; Tsukada, M.; Suzuki, N.; Shimamura, T.; Gao, L.; Koyanagi, J.; Komada, F.; Saito, S. Comparison of the cytotoxic activities of naturally occurring hydroxyanthraquinones and hydroxynaphthoquinones. Eur. J. Med. Chem. 2008, 43, 1206-1215. [CrossRef] [PubMed]

14. Plyta, Z.F.; Li, T.; Papageorgiou, V.P.; Mellidis, A.S.; Assimopoulou, A.N.; Pitsinos, E.N.; Couladouros, E.A. Inhibition of topoisomerase I by naphthoquinone derivatives. Bioorg. Med. Chem. Lett. 1980, 8, 3385-3390. [CrossRef]

15. Papageorgiou, V.P. Naturally occurring isohexenylnaphthazarin pigments: A new class of drugs. Planta Med. 1980, 38, 193-203. [CrossRef] [PubMed]

16. Rao, Z.; Liu, X.; Zhou, W.; Yi, J.; Li, S.S. Synthesis and antitumour activity of $\beta$-hydroxyisovalerylshikonin analogues. Eur. J. Med. Chem. 2001, 46, 3934-3941. [CrossRef] [PubMed]

17. Wang, X.M.; Lin, H.Y.; Kong, W.Y.; Guo, J.; Shi, J.; Huang, S.C.; Qi, J.L.; Yang, R.W.; Gu, H.W.; Yang, Y.H. Synthesis and biological evaluation of heterocyclic carboxylic acyl shikonin derivatives. Chem. Biol. Drug Res. 2014, 83, 334-343. [CrossRef] [PubMed]

18. Qiu, H.Y.; Wang, F.; Wang, X.; Sun, W.X.; Qi, J.L.; Pang, Y.J.; Yang, R.W.; Lu, G.H.; Wang, X.M.; Yang, Y.H. Design, synthesis and biological evaluation of chalcone containing shikonin derivatives as inhibitors of tubulin polymerization. Chem. Med. Chem. 2017, 12, 399-406. [CrossRef] [PubMed]

19. Lin, H.Y.; Han, H.W.; Sun, W.X.; Yang, Y.S.; Tang, C.Y.; Lu, G.H.; Qi, J.L.; Wang, X.M.; Lin, H.Y.; Han, H.W.; et al. Design and characterization of a-lipoic acyl shikonin ester twin drugs as tubulin and PDK1 dual inhibitors. Eur. J. Med. Chem. 2018, 144, 137-150. [CrossRef] [PubMed]

20. Baloch, S.K.; Ling, L.J.; Qiu, H.Y.; Ma, L.; Lin, H.Y.; Huang, S.C.; Qi, J.L.; Wang, X.M.; Lu, G.H.; Yang, Y.H. Synthesis and biological evaluation of novel shikonin ester derivatives as potential anti-cancer agents. RSC Adv. 2014, 4, 35588-35596.

21. Zhao, L.M.; Cao, F.X.; Jin, H.S.; Zhang, J.H.; Szwaya, J.; Wang, G. One-pot synthesis of 1,4-dihydroxy-2-(E-1-hydroxy-4-phenylbut-3-enyl)anthracene-9,10-diones as novel shikonin analogs and evaluation of their antiproliferative activities. Bioorg. Med. Chem. Lett. 2016, 26, 2691-2694. [CrossRef] [PubMed]

22. Ahn, B.Z.; Baik, K.U.; Kweon, G.R.; Kyu, L.; Hwang, B.D. Acylshikonin analogues: Synthesis and inhibition of DNA topoisomerase-I. J. Med. Chem 1995, 38, 1044-1047. [CrossRef] [PubMed] 
23. Kyong-Up, B.; Yong, S.G.; Yong, K.; Dai-Eun, S.; Byung-Zun, A. 2-Substituted naphthazarins; synthesis and antitumor activity. Arch. Pharm. Pharm. Med. Chem. 1997, 330, 377-382. [CrossRef]

24. Shen, C.C.; Syu, W.J.; Li, S.Y.; Lin, C.H.; Lee, G.H.; Sun, C.M. Antimicrobial activities of naphthazarins from Arnebia euchroma. J. Nat. Prod. 2002, 65, 1857-1862. [CrossRef] [PubMed]

25. Lin, H.Y.; Chen, W.; Shi, J.; Kong, W.Y.; Qi, J.L.; Wang, X.M.; Yang, Y.H. Design, synthesis and biological evaluation of cinnamic acyl shikonin derivatives. Chem. Biol. Drug Des. 2013, 81, 275-283. [CrossRef] [PubMed]

26. Brittelli, D.R. Phosphite-mediated in situ carboxyvinylation: A new general acrylic acid synthesis. J. Org. Chem. 1981, 46, 2514-2520. [CrossRef]

27. Van der Veken, P.; Senten, K.; Kertesz, I.; De Meester, I.; Lambeir, A.M.; Maes, M.B.; Scharpe, S.; Haemers, A.; Augustyns, K. Fluoro-olefins as peptidomimetic inhibitors of dipeptidyl peptidases. J. Med. Chem. 2005, 48, 1768-1780. [CrossRef] [PubMed]

28. Kann, N.; Rein, T.; Akermark, B.; Helquist, P. New functionalized Horner-Wadsworth-Emmons reagents: Useful building blocks in the synthesis of polyunsaturated aldehydes. A short synthesis of $( \pm)-(\mathrm{E}, \mathrm{E})$-coriolic acid. J. Org. Chem. 1990, 55, 5312-5523. [CrossRef]

29. Mayer, S.C.; Kreft, A.F.; Harrison, B.; Abou-Gharbia, M.; Antane, M.; Aschmies, S.; Atchison, K.; Chlenov, M.; Cole, D.C.; Comery, T.; et al. Discovery of begacestat, a Notch-1-sparing $\gamma$-secretase inhibitor for the treatment of Alzheimer's disease. J. Med. Chem. 2008, 51, 7348-7351. [CrossRef] [PubMed]

30. Rinner, B.; Gandolfi, G.; Meditz, K.; Frisch, M.T.; Wagner, K.; Ciarrocchi, A.; Torricelli, F.; Koivuniemi, R.; Niklander, J.; Liegl-Atzwanger, B.; et al. MUG-Mel2, a novel highly pigmented and well characterized NRAS mutated human melanoma cell line. Sci. Rep. 2017, 7, 1-11. [CrossRef] [PubMed]

31. Chang, H.Y.; Chi, J.T.; Dudoit, S.; Bondre, D.; Van de Rijn, M.; Botstein, D.; Brown, P.O. Diversity, topographic differentiation, and positional memory in human fibroblasts. Proc. Natl. Acad. Sci. USA 2002, 99, 12877-12882. [CrossRef] [PubMed]

32. Zhou, W.J.; Zhang, X.; Cheng, C.; Wang, F.; Wang, X.K.; Liang, Y.J.; To, K.K.W.; Zhou, W.; Huang, H.B.; Fu, L.W. Crizotinib (PF-02341066) reverses multidrug resistance in cancer cells by inhibiting the function of P-glycoprotein. Br. J. Pharmacol. 2012, 166, 1669-1683. [CrossRef] [PubMed]

33. Akiyode, O.; George, D.; Getti, G.; Boateng, J. Systematic comparison of the functional physico-chemical characteristics and biocidal activity of microbial derived biosurfactants on blood-derived and breast cancer cells. J. Colloid Interface Sci. 2016, 479, 221-233. [CrossRef] [PubMed]

34. Baell, J.B. Feeling nature's PAINS: Natural products, natural product drugs, and Pan Assay Interference Compounds (PAINS). J. Nat. Prod. 2016, 79, 616-628. [CrossRef] [PubMed]

35. Peer, D.; Karp, J.M.; Hong, S.; Farokhzad, O.C.; Margalit, R.; Langer, R. Nanocarriers as an emerging platform for cancer therapy. Nat. Nanotechnol. 2007, 2, 751-760. [CrossRef] [PubMed]

36. Li, H.; Tong, Y.; Bai, L.; Ye, L.; Zhong, L.; Duan, X.; Zhu, Y. Lactoferrin functionalized PEG-PLGA nanoparticles of shikonin for brain targeting therapy of glioma. Int. J. Biol. Macromol. 2018, 107, $204-211$. [CrossRef] [PubMed]

37. Kaur, A.; Jyoti, K.; Baldi, A.; Jain, U.K.; Chandra, R. Self-assembled nanomicelles of amphiphilic clotrimazole glycyl-glycine analogue augmented drug delivery, apoptosis and restrained melanoma tumour progression. Mater. Sci. Eng. C Mater. Biol. Appl. 2018, 89, 75-86. [CrossRef] [PubMed]

38. Shen, X.J.; Wang, H.B.; Ma, X.Q.; Chen, J.H. $\beta, \beta$-dimethylacrylshikonin induces mitochondria dependent apoptosis through ERK pathway in human gastric cancer SGC-7901 cells. PLoS ONE 2012, 7, e41773. [CrossRef] [PubMed]

39. Xiong, Y.; Ma, X.Y.; Zhang, Z.; Shao, Z.J.; Zhang, Y.Y.; Zhou, L.M. Apoptosis induced by $\beta, \beta$-dimethylacrylshikonin is associated with Bcl-2 and NF-kB in human breast carcinoma MCF-7 cells. Oncol. Lett. 2013, 6, 1789-1793. [CrossRef] [PubMed]

40. Plesca, D.; Mazumder, S.; Almasan, A. DNA damage response and apoptosis. Methods Enzymol. 2008, 446, 107-122. [PubMed]

41. Wu, Z.; Wu, L.; Li, L.; Tashiro, S.I.; Onodera, S.; Ikejima, T. P53-mediated cell cycle arrest and apoptosis induced by shikonin via a caspase-9-dependent mechanism in human malignant melanoma A375S2 cells. J. Pharmacol. Sci. 2004, 94, 166-176. [CrossRef] [PubMed] 
42. Yang, Y.Y.; He, H.Q.; Cui, J.H.; Nie, Y.J.; Wu, Y.X.; Wang, R.; Wang, G.; Zheng, J.N.; Ye, R.D.; Wu, Q.; et al. Shikonin derivative DMAKO-O5 inhibits Akt signal activation and melanoma proliferation. Chem. Biol. Drug Des. 2016, 6, 895-904. [CrossRef] [PubMed]

43. Zhen-Jun, S.; Yuan-Yuang, Z.; Ying, F.Y.; Ju, J.S.; Jiao, Y.; Wei, Z.X.; Jiang, C.; Yao, X.; Li-Ming, Z. $\beta, \beta$-Dimethylarcylshikonin exerts antitumor activity via Notch-1 signaling in vitro and in vivo. Biochem. Pharmacol. 2012, 84, 507-512. [CrossRef] [PubMed]

44. Kim, S.J.; Kim, J.M.; Shim, S.H.; Chang, H.I. Shikonin induces cell cycle arrest in human gastric cancer (AGS) by early growth response 1 (Erg1)-mediated p21 gene expression. J. Ethnopharmacol. 2014, 151, 1064-1071. [CrossRef] [PubMed]

45. Jing, H.; Sun, W.; Fan, J.; Zhang, Y.; Yang, J.; Jia, J.; Li, J.; Guo, J.; Luo, S.; Zheng, Y. Shikonin induces apoptosis of HaCaT cells via the mitochondrial, Erk and Akt pathway. Mol. Med. Rep. 2016, 13, 3009-3016. [CrossRef] [PubMed]

46. Rinner, B.; Kretschmer, N.; Knausz, H.; Mayer, A.; Boechzelt, H.; Hao, X.J.; Heubl, G.; Efferth, T.; Schaider, H.; Bauer, R. A petrol ether extract of the roots Onosma paniculata induces cell death in a caspase dependent manner. J. Ethnopharmacol. 2010, 129, 182-188. [CrossRef] [PubMed]

Sample Availability: Not available. 